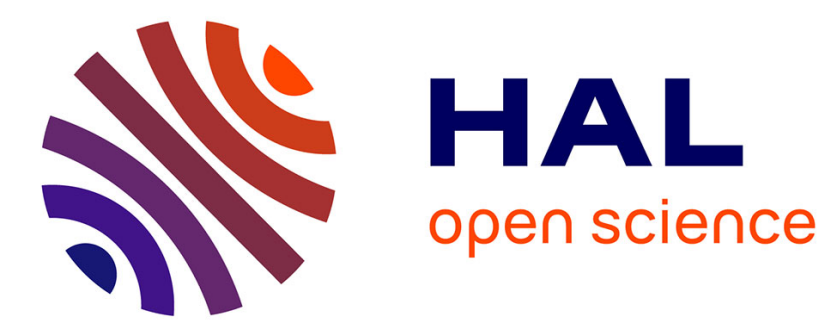

\title{
DART: Improvement of thermal infrared radiative transfer modelling for simulating top of atmosphere radiance
}

\author{
Ying-Jie Wang, Jean-Philippe Gastellu-Etchegorry
}

\section{To cite this version:}

Ying-Jie Wang, Jean-Philippe Gastellu-Etchegorry. DART: Improvement of thermal infrared radiative transfer modelling for simulating top of atmosphere radiance. Remote Sensing of Environment, 2020, 251, pp.112082. 10.1016/j.rse.2020.112082 . hal-03082738

\section{HAL Id: hal-03082738 \\ https://hal.science/hal-03082738}

Submitted on 18 Dec 2020

HAL is a multi-disciplinary open access archive for the deposit and dissemination of scientific research documents, whether they are published or not. The documents may come from teaching and research institutions in France or abroad, or from public or private research centers.
L'archive ouverte pluridisciplinaire HAL, est destinée au dépôt et à la diffusion de documents scientifiques de niveau recherche, publiés ou non, émanant des établissements d'enseignement et de recherche français ou étrangers, des laboratoires publics ou privés. 


\section{DART: improvement of thermal infrared radiative transfer}

\section{2 modelling for simulating top of atmosphere radiance}

3

4 Yingjie WANG ${ }^{1}$, Jean-Philippe Gastellu-Etchegorry ${ }^{1}$

5

6

7

8

9 Correspondence to: Yingjie WANG (yingjiewang1102@gmail.com)

Abstract

Land surface temperature (LST) is increasingly needed for studying the functioning of the

14 Earth's surface at local to global scale. Radiative transfer (RT) models that simulate top of 15 atmosphere (TOA) radiance are essential tools to derive accurate LST from thermal infrared 16 (TIR) signals of Earth observation (EO) satellites. DART (Discrete Anisotropic Radiative 17 Transfer) is one of the most accurate and comprehensive three-dimensional models that 18 simulate RT in the Earth-atmosphere system. Up to version 5.7.3, the mean absolute error 19 (MAE) of DART atmospheric TIR radiance of six standard atmospheres (USSTD76, TROPICAL, MIDDLATSUM, MIDDLATWIN, SUBARCSUM, SUBARCWIN) over $3.5 \mu \mathrm{m}$

$21-20 \mu \mathrm{m}$ was $3.1 \mathrm{~K}$ compared to the reference atmospheric RT model MODTRAN, which is 22 much larger than the $1 \mathrm{~K}$ accuracy needed by most LST applications. Also, the radiance error 23 reached $2.6 \mathrm{~K}$ for some TIR bands whereas the noise equivalent differential temperature (NeDT) 
of satellite TIR sensor is usually less than $0.4 \mathrm{~K}$. Recently, the DART atmospheric RT modelling was greatly improved by (1) introducing the equivalent absorption cross-section of five most absorbing gases $\left(\mathrm{H}_{2} \mathrm{O}, \mathrm{CO}_{2}, \mathrm{O}_{3}, \mathrm{CH}_{4}, \mathrm{~N}_{2} \mathrm{O}\right)$, and (2) implementing a double-layer thermal emission method. The MAE of DART atmospheric TIR radiance of six standard atmospheres and actual atmospheres over France and the Mediterranean Sea is now better than $1.0 \mathrm{~K}$. The band radiance error is less than $0.2 \mathrm{~K}$ in the EO satellite TIR bands. DART is still accurate if the temperature profiles of standard atmospheres are offset by less than $6 \mathrm{~K}$ and if the viewing zenith angle is less than $50^{\circ}$. In short, the improved DART meets the requirements of both LST applications, and present and future TIR EO satellite missions. It is already available to scientists (https://dart.omp.eu).

Keywords: DART, radiative transfer, atmosphere, thermal infrared, absorption cross-section, MODTRAN

\section{Introduction}

Land surface temperature (LST) has a wide range of applications in different fields: evapotranspiration, soil moisture, precision agriculture, urban climate, river environments, oceanography, etc. (Dugdale, 2016; Khanal et al., 2017; Kilpatrick et al., 2015; Voogt and Oke, 2003; Wang et al., 2006; Wang and Qu, 2009). Due to its high temporal resolution, broad coverage and low cost, thermal infrared (TIR) remote sensing is an ideal tool to measure LST (Li et al., 2013). Therefore, an increasing number of space missions embark sensors with TIR bands. For example, the Trishna mission of French Space Agency (CNES) and Indian Space Research Organization (ISRO), to be launched in 2024-2025, will embark a sensor that has four TIR bands with noise equivalent differential temperature (NeDT) of $0.3 \mathrm{~K}$ at $300 \mathrm{~K}$ (Lagouarde 
et al., 2018). The sea and land surface temperature radiometer on board the European Space Agency (ESA) Sentinel 3 satellite has three TIR bands with NeDT of $0.05 \mathrm{~K}$ at $270 \mathrm{~K}$ (Donlon et al., 2012). The National Aeronautics and Space Administration (NASA) Landsat 8 satellite has a TIR sensor with NeDT of $0.4 \mathrm{~K}$ at $300 \mathrm{~K}$ (Irons et al., 2012). Landsat 9 satellite, due to be launched on 2021, should embark a TIR sensor similar to the Landsat 8 TIR sensor (McCorkel et al., 2018).

Most LST applications require accuracy less than $1 \mathrm{~K}$ (Sobrino et al., 2016). Although the sensibility (NeDT) of most satellite TIR sensors is less than $0.4 \mathrm{~K}$, the LST derived from remotely sensed data is usually less accurate, mainly due to atmospheric conditions, topography, land surface heterogeneity, and directional effects (Bento et al., 2017; Bonafoni, 2016; Ermida et al., 2018; He et al., 2019; Price, 1983; Vermote et al., 2002). Therefore, there is a need to better link LST and observations from satellite TIR sensors. Physical models that accurately simulate TIR radiative transfer (RT) in the Earth-atmosphere system are essential tools. However, most RT models are either for the atmosphere (e.g., 4A/OP, MODTRAN, LBLRTM, RFM, ARTS) or for the Earth surfaces (e.g., Rayspread, RAPID3, FLiES, SAIL) (Berk et al., 2015; Buehler et al., 2018; Clough et al., 2005; Huang, 2018; Kobayashi and Iwabuchi, 2008; Scott, 1974; Verhoef, 1984; Vincent and Dudhia, 2017; Widlowski et al., 2006). DART (Discrete Anisotropic Radiative Transfer) is one of the few models that simulate RT in the Earth-atmosphere system. Its Earth surface RT modelling accuracy in the short and long waves was already verified in the four phases of the RAdiative transfer Model Intercomparison (RAMI) project (Widlowski et al., 2015, 2013, 2007) and in experiments (Guillevic et al., 2003, 2013). Its atmospheric short wave RT modelling was validated with the reference atmospheric RT model MODTRAN-5 (Gastellu-Etchegorry et al., 2017; Grau and Gastellu-Etchegorry, 2013). 
However, as presented below, its atmospheric RT modelling in the TIR region did not meet the requirements of LST applications and TIR Earth observation (EO) satellite missions.

DART simulates atmosphere in three altitude regions: (1) the bottom atmosphere inside the Earth scene voxel matrix, (2) the mid-atmosphere made of voxels of any size, and (3) the high atmosphere made of layers. Voxels in the mid-atmosphere allows DART to simulate the spatial heterogeneity of the atmosphere backscattering. Any atmosphere layer is homogeneously filled with gasses, aerosols and/or clouds that have specific physical (i.e., temperature, pressure, density) and spectral (i.e., absorption/scattering extinction coefficient, scattering phase function) properties. The atmospheric RT modelling relies on the spectral application of Beer's law and band mean optical properties (Gastellu-Etchegorry et al., 2004). The extinction coefficient at each layer is calculated so that the use of Beer's law gives the same vertical atmospheric transmittance as MODTRAN, assuming that the cross-section of the gases is independent of pressure and temperature. Although initial methodology simulates accurate atmospheric radiance in short waves, the TIR radiance could differ significantly from MODTRAN. For example, in [3.5 $\mu \mathrm{m}-20 \mu \mathrm{m}]$ region, its mean absolute error (MAE) of top of atmosphere (TOA) atmospheric TIR brightness temperature (BT) of the USSTD76 atmosphere was $3.1 \mathrm{~K}$, which is much larger than LST application requirements. This is due to three approximations: (1) gas absorption cross-section is independent of pressure and temperature; (2) gas absorption transmittance is computed with Beer's law and band mean optical properties; (3) the method that computes layer thermal emission is only suited to optically thin atmosphere.

Actually, the gas absorption cross-section varies with pressure and temperature due to the Doppler and Lorentz broadening. Many atmospheric RT models, including MODTRAN, compute the pressure- and temperature-dependent gas absorption cross-section lines based on 
the high resolution (spectral resolution up to $0.001 \mathrm{~cm}^{-1}$ ) spectroscopic databases, such as HITRAN and GEISA (Jacquinet-Husson et al., 2016; Rothman et al., 2009). These models compute the absorption transmittance with either the exact gas absorption cross-section lines (line-by-line models like 4A/OP) or the statistically determined gas absorption cross-section lines (band models like MODTRAN). Therefore, their absorption transmittance is usually more accurate than the absorption transmittance calculated with Beer's law and band mean absorption cross-sections. In addition, the thermal emission of an atmosphere layer computed with the layer mean temperature is incorrect if the layer is optically thick. MODTRAN improved it by computing the layer thermal emission with the "linear-in-optical depth" method (Clough et al., 1992).

This paper presents two major improvements of DART TIR RT modelling in order to meet the requirements of LST applications and TIR EO satellite missions: (1) introduction of the pressure- and temperature-dependent equivalent absorption cross-section of five most absorbing gases $\left(\mathrm{H}_{2} \mathrm{O}, \mathrm{CO}_{2}, \mathrm{O}_{3}, \mathrm{CH}_{4}, \mathrm{~N}_{2} \mathrm{O}\right)$; (2) implementation of an efficient double-layer thermal emission method that is adapted to most atmospheric conditions. Limits of these two improvements are also discussed. Then, the improved DART is compared with MODTRAN-5 using standard atmosphere profiles and the actual atmosphere profiles from ECMWF reanalysis dataset.

\section{DART model}

DART (https://dart.omp.eu) has been developed at CESBIO since 1992 (Gastellu-Etchegorry et al., 2017, 1996). It is one of the most accurate and comprehensive 3D RT models for the remote sensing community. It simulates the radiative budget, bi-directional reflectance factor 
123 (BRF) and images at any altitude and along any viewing direction for 3D natural and urban

124 scenes, with topography and atmosphere (Figure 1), from visible to thermal infrared region. For

125 that, it uses an iterative discrete ordinate method (DOM) that tracks radiation fluxes along a

126 finite number of discrete directions. It also simulates terrestrial and aero-spatial LiDAR signal

127 (point cloud, waveform, photon counting) with an approach that combines Monte Carlo method 128 and DOM.

129

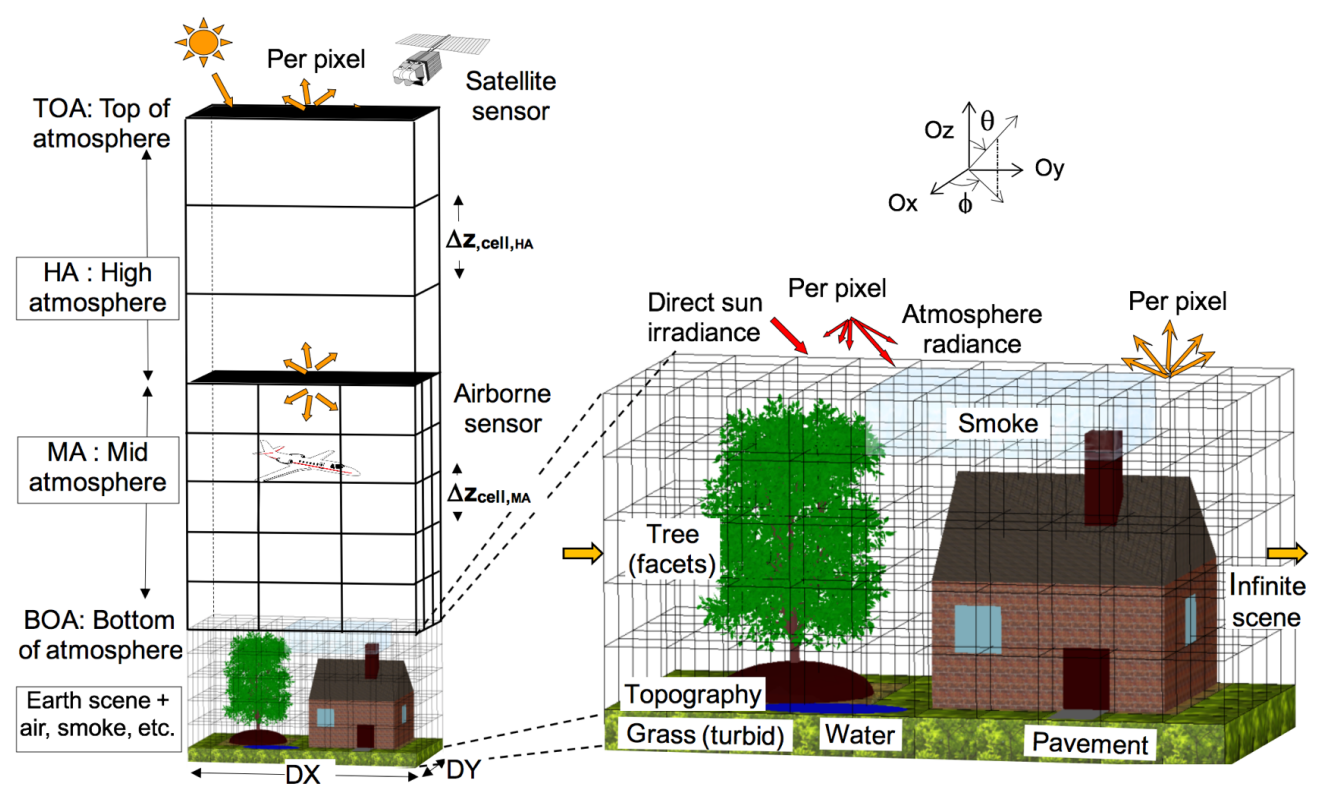

Figure 1. DART 3D mock-up and voxel matrix. Atmosphere is separated in three altitude regions: high atmosphere (HA) made of layers, mid-atmosphere (MA) made of voxels of any size, and bottom atmosphere (BA) in the Earth scene. Earth scene elements are made of facets (triangles), and/or fluid and turbid vegetation voxels. The voxel matrix is introduced to optimize ray tracing.

\subsection{DART atmosphere profiles}

DART simulates the atmosphere as three superimposed volumes: (1) bottom atmosphere (BA) inside the Earth scene voxel matrix, (2) mid-atmosphere (MA) made of voxels, and (3) high 
140 atmosphere (HA) made of layers (Figure 1). The geometry of MA and HA (i.e., number of

141 layers, layer thickness, voxel size) is either user-defined or analytically computed. The

142 geometry of BA is the same as the Earth scene. The DART atmosphere SQL database stores

143 vertical profiles of atmospheric constituents (i.e., temperature $T_{D B}(z)$, pressure $P_{D B}(z)$,

144 number density $N_{m_{i}, D B}(z)$ per gas $m_{i}$, relative density $\rho_{m, D B}^{S}(z)$ of scattering gases to air at

145 standard temperature and pressure and aerosol extinction coefficient profile $\alpha_{p, D B}^{e}(z)$ at 550

$146 \mathrm{~nm}$ ). These profiles are stored at 36 altitude levels ( 0 to $25 \mathrm{~km}$ with $1 \mathrm{~km}$ interval, 30 to $60 \mathrm{~km}$

147 with $5 \mathrm{~km}$ interval and 3 levels at $70 \mathrm{~km}, 80 \mathrm{~km}$ and $100 \mathrm{~km}$ ) for:

148 - six standard atmospheres (Anderson et al., 1986): (1) TROPICAL: Tropical $\left(15^{\circ} \mathrm{N}\right.$ annual

149 average), (2) MIDLATSUM: Mid-Latitude Summer (45N July), (3) MIDLATWIN: Mid-

150 Latitude Winter ( $45^{\circ} \mathrm{N}$ January), (4) SUBARCSUM: Sub-Arctic Summer (60 N July), (5)

151 SUBARCWIN: Sub-Arctic Winter (60 N January), and (6) USSTD76: US Standard 1976.

152 - five aerosol models (Shettle and Fenn, 1979): (1) Rural, (2) Urban, (3) Maritime, (4)

153 Tropospheric and (5) Fog.

155 The DART atmosphere SQL database also stores the spectral optical properties of atmospheric 156 constituents (i.e., gas: vertical absorption transmittance $t_{m_{i}, D B}^{a}(\lambda)$ per gas $m_{i}$, vertical 157 scattering transmittance $t_{m, D B}^{S}(\lambda)$; aerosol: vertical optical depth $\tau_{p, D B}(\lambda)$, single scattering 158 albedo $\omega_{p, D B}(\lambda)$, asymmetry factors of double Henyey-Greenstein phase function) from 10 to $15940000 \mathrm{~cm}^{-1}$ with a spectral resolution of $1 \mathrm{~cm}^{-1}$. They were derived from MODTRAN 160 simulations and LOWTRAN source code for the six standard atmospheres and for the five 161 aerosol models per standard atmosphere. The optical properties and vertical profiles of gases 162 and aerosols derived from reanalysis datasets (e.g., ECMWF reanalysis: https://www.ecmwf.int) 163 and measurements (e.g., Aeronet: https://aeronet.gsfc.nasa.gov) can also be imported into the 164 DART atmosphere database. 
166 The atmosphere properties at any altitude $z$ are interpolated by the multi-quadric RBF (Radial

167 Basis Function) (Press et al., 2007) using vertical profiles and optical properties in the SQL

168 database. The band (central wavelength $\lambda$, bandwidth $\Delta \lambda$ ) mean optical properties (i.e., vertical

169 absorption transmittance $t_{m_{i}}^{a}(\lambda)$ of each gas $m_{i}$, gas vertical scattering transmittance $t_{m}^{s}(\lambda)$,

170 aerosol vertical optical depth $\tau_{p}(\lambda)$ ) are computed (trapezoidal integration) using the database

171 spectral vertical transmittance $t_{m_{i}, D B}^{a}\left(\lambda^{\prime}\right), t_{m, D B}^{S}\left(\lambda^{\prime}\right)$ and optical depth $\tau_{p, D B}\left(\lambda^{\prime}\right)$ at $1 \mathrm{~cm}^{-1}$

172 spectral resolution in the spectral bin $\Delta \lambda$ :

$$
\begin{aligned}
t_{m_{i}}^{a}(\lambda) & =\frac{\int_{\lambda-\Delta \lambda / 2}^{\lambda+\Delta \lambda / 2} t_{m_{i}, D B}^{a}\left(\lambda^{\prime}\right) d \lambda^{\prime}}{\Delta \lambda}, t_{m}^{S}(\lambda)=\frac{\int_{\lambda-\Delta \lambda / 2}^{\lambda+\Delta \lambda / 2} t_{m, D B}^{s}\left(\lambda^{\prime}\right) d \lambda^{\prime}}{\Delta \lambda} \\
\tau_{p}(\lambda) & =\frac{\int_{\lambda-\Delta \lambda / 2}^{\lambda+\Delta \lambda / 2} \tau_{p, D B}\left(\lambda^{\prime}\right) d \lambda^{\prime}}{\Delta \lambda}
\end{aligned}
$$

173

174 In DART flux tracking mode, the extinction coefficient $\alpha$ (i.e., total $\alpha^{e}$, absorption $\alpha^{a}$ and

175 scattering $\alpha^{S}$ extinction coefficient) are constant values per layer $j$ such that their use with

176 Beer's law gives the band vertical transmittance and optical depth computed in Eq. (1).

$$
\begin{aligned}
& \alpha_{j, m_{i}}^{a}(\lambda)=\frac{-\ln \left(t_{m_{i}}^{a}(\lambda)\right)}{z_{j}-z_{j-1}} \cdot \frac{\int_{z_{j-1}}^{z_{j}} \sigma_{m_{i}}^{a}(\lambda) \cdot N_{m_{i}, D B}(z) d z}{\int_{0}^{\infty} \sigma_{m_{i}}^{a}(\lambda) \cdot N_{m_{i}, D B}(z) d z} \\
& \alpha_{j, m}^{s}(\lambda)=\frac{-\ln \left(t_{m}^{S}(\lambda)\right)}{z_{j}-z_{j-1}} \cdot \frac{\int_{z_{j-1}}^{z_{j}} \sigma_{m}^{S}(\lambda) \cdot N_{m}^{S}(z) d z}{\int_{0}^{\infty} \sigma_{m}^{S}(\lambda) \cdot N_{m}^{S}(z) d z}=\frac{-\ln \left(t_{m}^{S}(\lambda)\right)}{z_{j}-z_{j-1}} \cdot \frac{\int_{z_{j-1}}^{z_{j}} \rho_{m, D B}^{S}(z) d z}{\int_{0}^{\infty} \rho_{m, D B}^{S}(z) d z} \\
& \alpha_{j, p}^{e}(\lambda)=\frac{\tau_{p, D B}(\lambda)}{z_{j}-z_{j-1}} \cdot \frac{\int_{z_{j-1}}^{z_{j}}}{\int_{0}^{\infty} \alpha_{p, D B}^{e}(z) d z}
\end{aligned}
$$

178 The Newton-Cotes integration method is used in Eq. (2) with 10 interpolated equal-distance

179 values per layer (Abramowitz and Stegun, 1948) assuming that the absorption cross-section 

$\sigma_{m_{i}}^{a}(\lambda)$ of gas $m_{i}$ only depends on wavelength. The gas scattering cross-section $\sigma_{m}^{S}(\lambda)$ only

181 depends on wavelength and gas composition (Bodhaine et al., 1999). Therefore, $\sigma_{m}^{s}(\lambda) \cdot N_{m}^{s}(z)$, 182 with $N_{m}^{s}(z)$ being the number density of scattering gases at altitude $z$, is proportional to the 183 relative density of scattering gases $\rho_{m, D B}^{S}(z)$.

184

185 Then, the total gas extinction coefficient $\alpha_{j, m}^{e}(\lambda)$, aerosol absorption $\alpha_{j, p}^{a}(\lambda)$ and scattering 186 $\alpha_{j, p}^{S}(\lambda)$ extinction coefficient and total extinction coefficient $\alpha_{j}^{e}(\lambda)$ are computed per layer:

$$
\begin{aligned}
& \alpha_{j, m}^{e}(\lambda)=\alpha_{j, m}^{a}(\lambda)+\alpha_{j, m}^{s}(\lambda), \alpha_{j, m}^{a}(\lambda)=\sum_{m_{i}} \alpha_{j, m_{i}}^{a}(\lambda) \\
& \alpha_{j, p}^{a}(\lambda)=\alpha_{j, p}^{e}(\lambda) \cdot\left(1-\omega_{p, D B}(\lambda)\right), \alpha_{j, p}^{s}(\lambda)=\alpha_{j, p}^{e}(\lambda) \cdot \omega_{p, D B}(\lambda) \\
& \alpha_{j}^{e}(\lambda)=\alpha_{j, m}^{e}(\lambda)+\alpha_{j, p}^{e}(\lambda)
\end{aligned}
$$

187

188 As explained in section 4, in order to improve the modelling of thermal emission, we adapted

189 the continuous optical depth profiles per atmosphere layer computed in the DART LiDAR

190 mode (Gastellu-Etchegorry et al., 2015). Hence, $\alpha_{j}^{e}(\lambda, h)$ and $\tau_{j}(\lambda, h)=\int_{0}^{\Delta z_{j}} \alpha_{j}^{e}(\lambda, h) d h$ are

191 continuous functions per atmosphere layer $j$ defined as

$192 \tau_{j}(\lambda, h)=A_{j}(\lambda) \cdot h^{3}+B_{j}(\lambda) \cdot h^{2}+C_{j}(\lambda) \cdot h+D_{j}(\lambda)$ and $\alpha_{j}^{e}(\lambda, h)=-3 A_{j}(\lambda) \cdot h^{2}-2 B_{j}(\lambda) \cdot h-C_{j}(\lambda)$,

193 where $h$ is the relative altitude in layer $j$, with $h=0$ at the bottom of layer $j$ and $h=\Delta z_{j}$ at the top

194 of layer $j$. The verification of the four equalities $\tau(\lambda, 0)=\Delta \tau_{j}(\lambda), \tau\left(\lambda, \Delta z_{j}\right)=0$,

$195 \alpha_{j}^{e}(\lambda, 0)=\alpha_{z_{j-1}}^{e}(\lambda), \alpha_{j}^{e}\left(\lambda, \Delta z_{j}\right)=\alpha_{z_{j}}^{e}(\lambda)$ derives the coefficients $A_{j}(\lambda), B_{j}(\lambda), C_{j}(\lambda)$ and $D_{j}(\lambda)$

196 (Eq. (4)).

$$
A_{j}(\lambda)=\frac{2 \Delta \tau_{j}(\lambda)-\left(\alpha_{z_{j-1}}^{e}(\lambda)+\alpha_{z_{j}}^{e}(\lambda)\right) \Delta z_{j}}{\Delta z_{j}^{3}}, B_{j}(\lambda)=\frac{-3 A_{j}(\lambda) \Delta z_{j}^{2}+\alpha_{z_{j-1}}^{e}(\lambda)-\alpha_{z_{j}}^{e}(\lambda)}{2 \Delta z_{j}}
$$




$$
C_{j}(\lambda)=-\alpha_{z_{j-1}}^{e}(\lambda), D_{j}(\lambda)=\Delta \tau_{j}(\lambda)
$$

197 coefficient.

$$
\begin{aligned}
W_{j}(\Omega, \lambda)=\int_{0}^{\Delta z_{j}} L_{B}\left(T_{j}, \lambda\right) \cdot \alpha_{j}^{a}(\lambda) \cdot \Delta S \cdot \Delta \Omega \cdot e^{-\int_{z}^{\Delta z_{j}} \alpha_{j}^{e}(\lambda) \frac{d z}{\mu}} d z \\
\quad=\left(1-\omega_{j}(\lambda)\right) \cdot L_{B}\left(T_{j}, \lambda\right) \cdot\left[1-e^{-\frac{\Delta \tau_{j}}{\mu}}\right] \cdot \mu \cdot \Delta S \cdot \Delta \Omega
\end{aligned}
$$

209 where $L_{B}\left(T_{j}, \lambda\right)$ (unit: $W / \mathrm{m}^{2} / \mathrm{sr} / \mu \mathrm{m}$ ) is the spectrally averaged Planck function at layer mean temperature $T_{j} . \Delta \tau_{j}$ is the optical depth of the atmosphere layer $j . \mu=\cos (\theta)$.

Figure 2. DART horizontally homogeneous atmosphere layer with layer thickness $\Delta z_{j}$. The upper and lower boundary parameters are marked.

\subsection{Layer thermal emission}

layer mean temperature $T_{j}$ and two optical properties: single scattering albedo $\omega_{j}(\lambda)=\frac{\alpha_{j}^{S}(\lambda)}{\alpha_{j}^{e}(\lambda)}$ and extinction coefficient $\alpha_{j}^{e}(\lambda)=\alpha_{j}^{a}(\lambda)+\alpha_{j}^{s}(\lambda)$, with $\alpha_{j}^{a}(\lambda)=\alpha_{j, m}^{a}(\lambda)+\alpha_{j, p}^{a}(\lambda)$ the total absorption extinction coefficient and $\alpha_{j}^{S}(\lambda)=\alpha_{j, m}^{S}(\lambda)+\alpha_{j, p}^{S}(\lambda)$ the total scattering extinction layer $j$

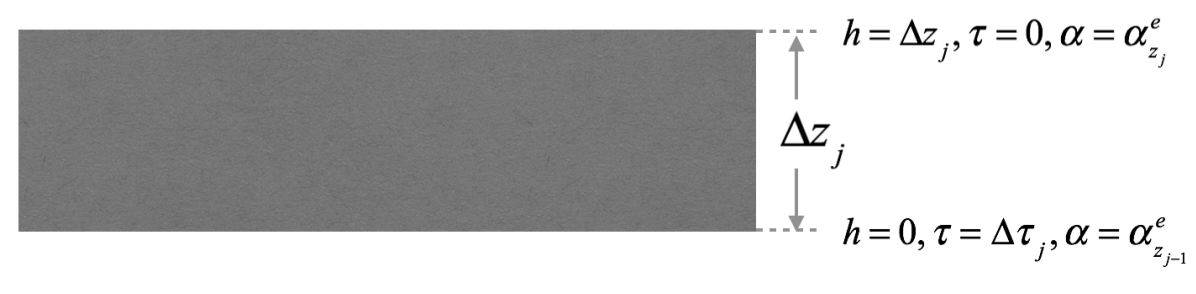




\subsection{RT in the Earth-atmosphere system}

214 RT modelling in the Earth-atmosphere system involves five major steps (Figure 3): (1) Sun 215 illumination and atmosphere thermal emission; (2) Earth surface RT; (3) Earth-atmosphere 216 radiative coupling and atmosphere backscattering; (4) Earth surface RT of the backscattered 217 radiation; (5) Transfer of bottom of atmosphere (BOA) radiation to any altitude, including TOA 218 (Grau and Gastellu-Etchegorry, 2013).
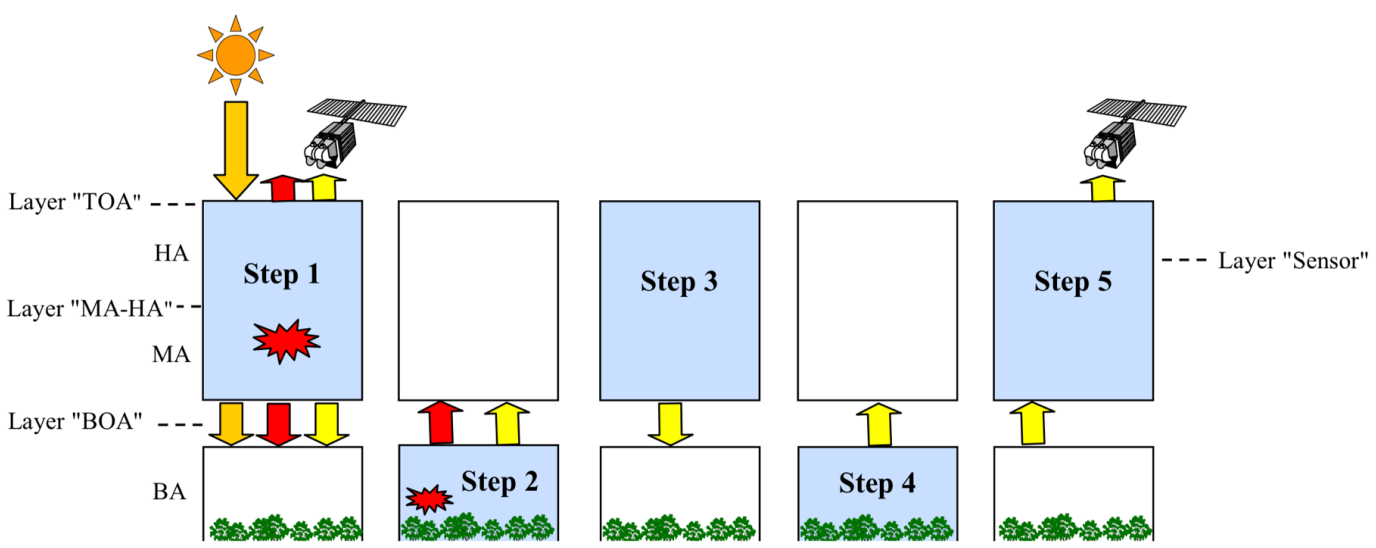

Figure 3. Major steps for modelling the RT in the Earth-atmosphere system. Red colour indicates thermal emission (steps 1 and 2), orange colour indicates solar incident radiation, and yellow colour indicates thermal and/or solar radiation that is scattered.

\section{Initial DART atmospheric RT modelling accuracy}

DART atmospheric RT modelling accuracy was assessed using MODTRAN-5 since it is one of the most accurate atmospheric RT models, with transmittance accuracy \pm 0.005 , radiance accuracy $\pm 2 \%$ and thermal brightness temperature (BT) accuracy better than $1 \mathrm{~K}$ (Berk et al., 2008, 2005, 1987). In the short waves (i.e., [0.4 $\mu \mathrm{m}, 3.0 \mu \mathrm{m}]$ ), with ground albedo 0.5, TOA nadir reflectance absolute difference between DART and MODTRAN-5 was less than 0.004, 
which meets MODTRAN-5 accuracy (Gastellu-Etchegorry et al., 2017; Grau and Gastellu-

232 Etchegorry, 2013). Here, the comparison is extended to TIR region from $3.5 \mu \mathrm{m}$ to $20 \mu \mathrm{m}$, 233 using DART version 5.7.3, hereafter called "initial DART". To analyse pure gas atmosphere 234 emission, MODTRAN-5 and DART were run with thermal emission mode, no aerosol, the 235 Earth skin temperature is $0 \mathrm{~K}$, surface albedo is 0 , and the atmosphere layer depth is equal to 1 $236 \mathrm{~km}$ from 0 to $25 \mathrm{~km}$, and $5 \mathrm{~km}$ from $30 \mathrm{~km}$ to $100 \mathrm{~km}$. Figure 4 shows DART and MODTRAN2375 TOA and BOA TIR radiance spectra and the residuals, for four standard atmospheres 238 (USSTD76, TROPICAL, MIDLATSUM, SUBARCWIN). The mean absolute error (MAE) 239 and mean absolute relative error (MARE) instead of the root-mean-square-error (RMSE) are 240 used to quantify DART and MODTRAN-5 differences since they bring a more unambiguous 241 information (Willmott and Matsuura, 2005). For a variable $X(q)($ e.g., BT, radiance) at band $q$ 242 and $Q$ spectral bands:

$$
\begin{aligned}
& \text { MAE }=\frac{1}{Q} \cdot \sum_{q=1}^{Q}\left|X_{\text {DART }}(q)-X_{\text {MODTRAN5 }}(q)\right| \\
& \text { MARE }=\frac{1}{Q} \cdot \sum_{q=1}^{Q} \frac{\left|X_{\text {DART }}(q)-X_{\text {MODTRAN5 }}(q)\right|}{X_{\text {MODTRAN5 }}(q)} \cdot 100 \%
\end{aligned}
$$

244 Note that the error defined in Eq. (6) is relative to MODTRAN, one should take into account 245 the accuracy of MODTRAN in practical application. 


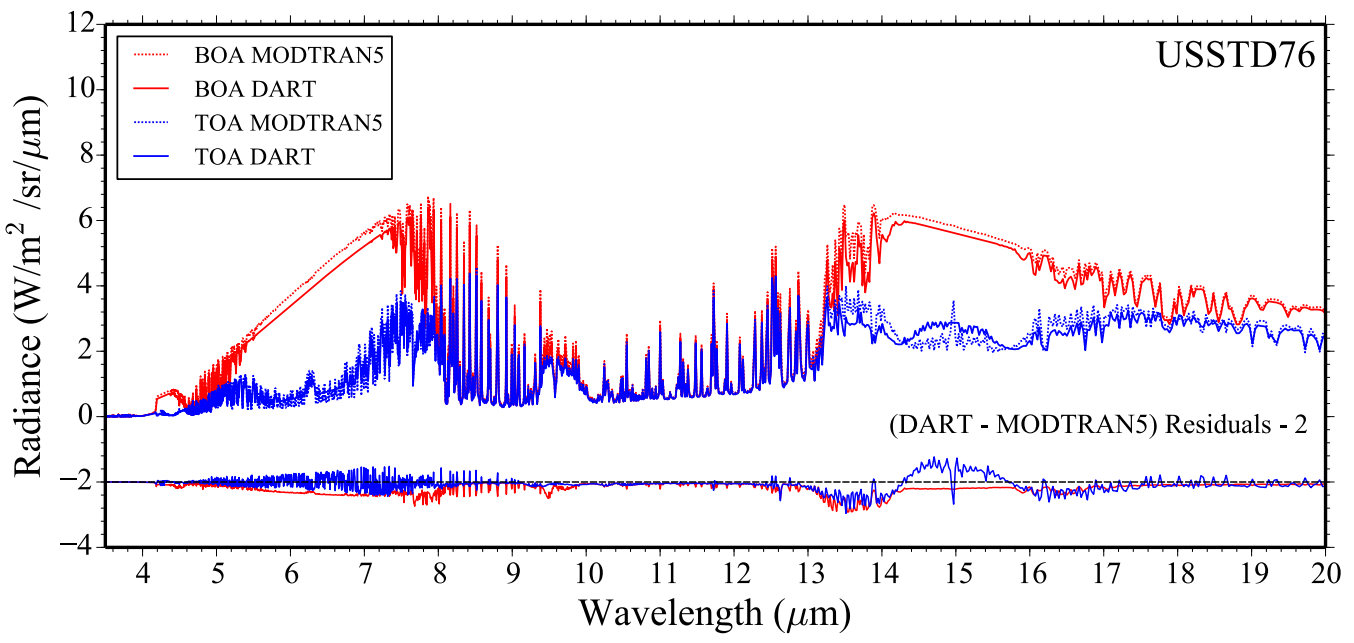

a)

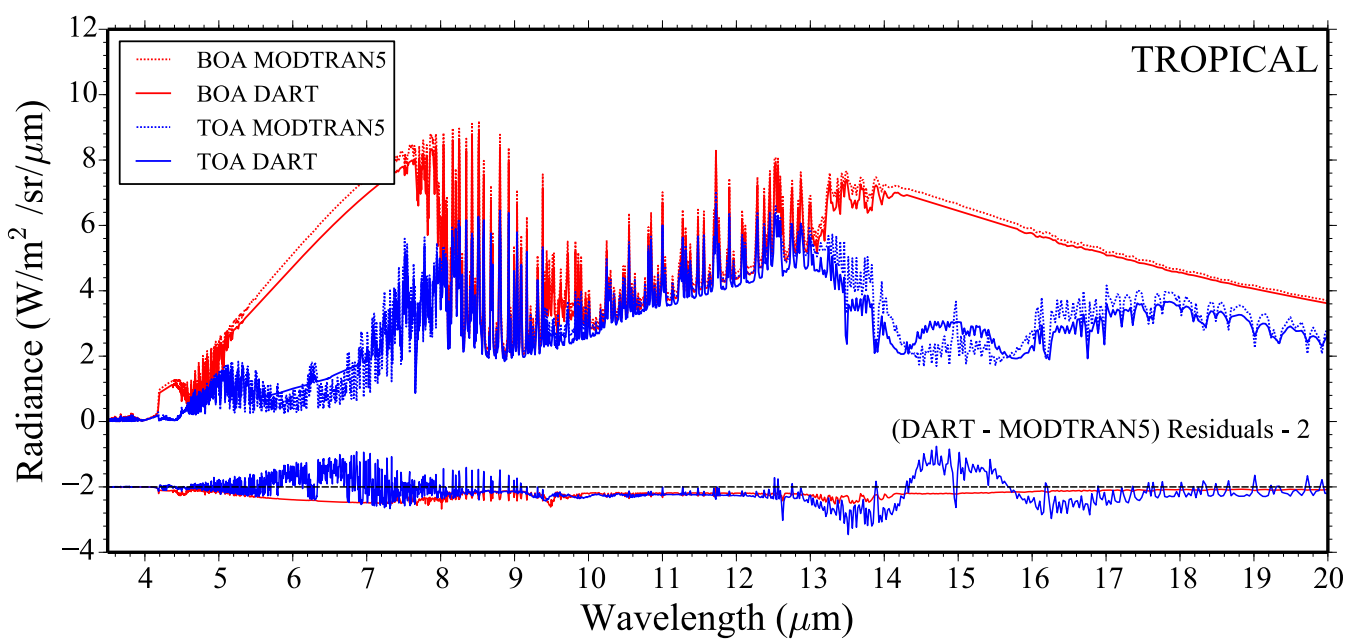

b)

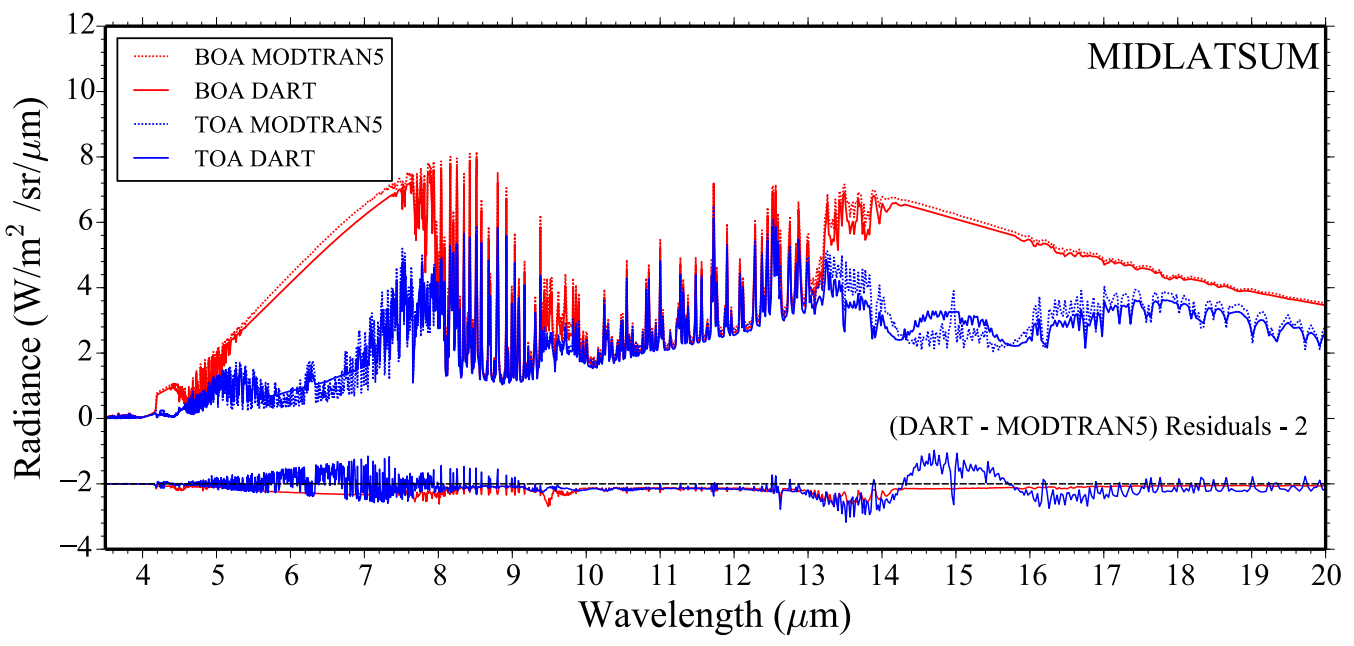

c) 


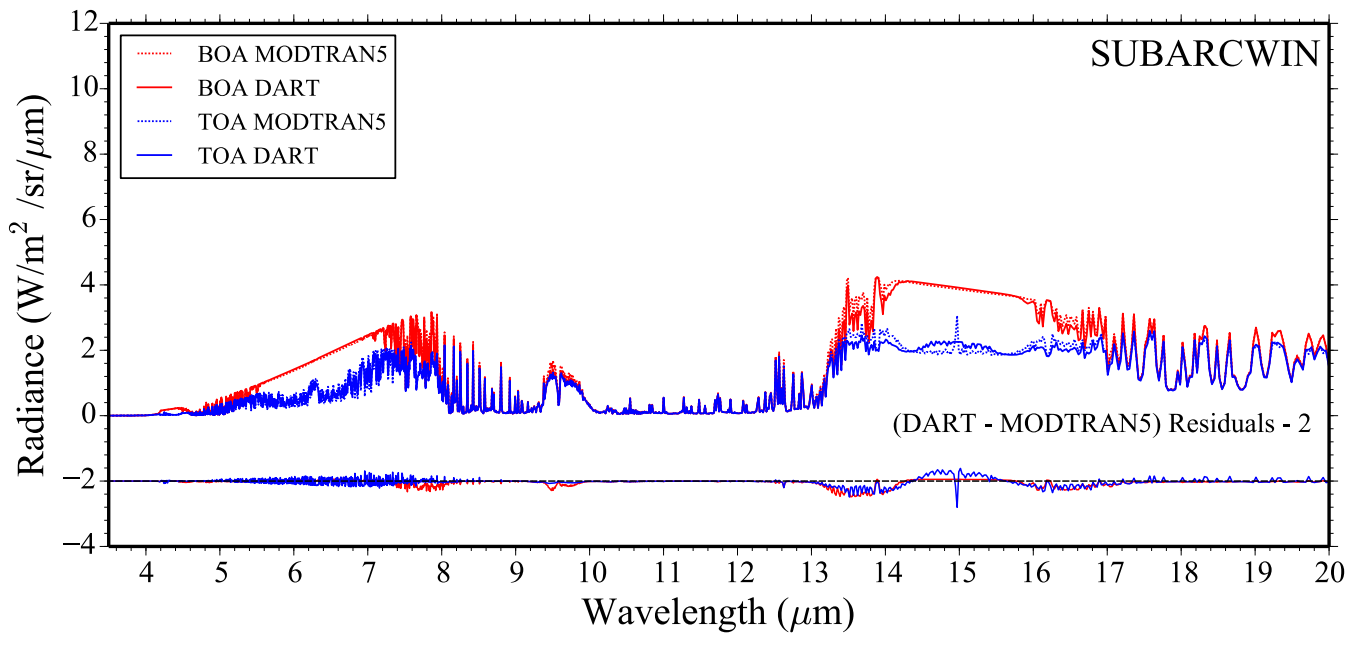

Figure 4. Initial DART and MODTRAN-5 TOA / BOA TIR radiance in [3.5 $\mu \mathrm{m}, 20 \mu \mathrm{m}]$ region for USSTD76 (a), TROPICAL (b), MIDLATSUM (c) and SUBARCWIN (d) atmospheres. 1 $\mathrm{cm}^{-1}$ spectral resolution. DART and MODTRAN-5 configurations are detailed in section 3.

Table 1 summarizes the "Initial DART - MODTRAN-5" MAEs for BT and MAREs for 251 radiance, for six standard atmospheres. For most standard atmospheres, BT MAEs are larger 252 than $2.0 \mathrm{~K}$ and $1.5 \mathrm{~K}$ for TOA and BOA radiance spectra, respectively. The maximal BT MAE 253 occur for the TROPICAL atmosphere at TOA level with Max (BT MAE) $=4.7 \mathrm{~K}$.

Table 1. TOA and BOA BT MAE and radiance MARE of initial DART in [3.5 $\mu \mathrm{m}, 20 \mu \mathrm{m}]$ region for six standard atmospheres. MODTRAN-5 results are the reference.

\begin{tabular}{ccccc}
\hline \multirow{2}{*}{ Atmosphere } & \multicolumn{2}{c}{ BT MAE } & \multicolumn{2}{c}{ Radiance MARE } \\
& TOA $(\mathrm{K})$ & BOA $(\mathrm{K})$ & TOA $(\%)$ & BOA $(\%)$ \\
\hline USSTD76 & $3.1 \mathrm{~K}$ & $2.7 \mathrm{~K}$ & 12.6 & 8.6 \\
TROPICAL & $4.7 \mathrm{~K}$ & $2.4 \mathrm{~K}$ & 18.9 & 6.8 \\
MIDLATSUM & $3.8 \mathrm{~K}$ & $2.1 \mathrm{~K}$ & 15.0 & 6.1
\end{tabular}




\begin{tabular}{ccccc} 
MIDLATWIN & $2.3 \mathrm{~K}$ & $1.8 \mathrm{~K}$ & 10.1 & 6.3 \\
SUMARCSUM & $2.9 \mathrm{~K}$ & $2.3 \mathrm{~K}$ & 11.5 & 7.1 \\
SUMARCWIN & $1.8 \mathrm{~K}$ & $1.3 \mathrm{~K}$ & 8.0 & 5.2 \\
Average & $3.1 \mathrm{~K}$ & $2.1 \mathrm{~K}$ & 12.7 & 6.7 \\
\hline
\end{tabular}

258 DART and MODTRAN-5 TOA / BOA radiance values diverge more in absorbing spectral 259 regions than in non-absorbing spectral regions. For example, Table 2 shows that very large BT 260 differences, up to $7 \mathrm{~K}$, occur in the four absorbing spectral regions: ABS1 ([3.5 $\mu \mathrm{m}, 4.5 \mu \mathrm{m}])$, $261 \operatorname{ABS} 2([6 \mu \mathrm{m}, 7 \mu \mathrm{m}]), \operatorname{ABS} 3([9 \mu \mathrm{m}, 10 \mu \mathrm{m}])$ and ABS4 $([14 \mu \mathrm{m}, 16 \mu \mathrm{m}])$ for the USSTD76 262 atmosphere. Table 2. TOA and BOA BT MAE and radiance MARE of initial DART in four TIR absorbing bands 265 (ABS1, ABS2, ABS3, ABS4) for the USSTD76 atmosphere. MODTRAN-5 results are the reference.

\begin{tabular}{|c|c|c|c|c|c|c|}
\hline \multirow{2}{*}{$\begin{array}{c}\text { Absorption } \\
\text { band }\end{array}$} & \multirow{2}{*}{$\begin{array}{c}\text { Central } \\
\text { wavelength }\end{array}$} & \multirow{2}{*}{ Bandwidth } & \multicolumn{2}{|c|}{ BT MAE } & \multicolumn{2}{|c|}{ Radiance MARE } \\
\hline & & & TOA $(\mathrm{K})$ & $\mathrm{BOA}(\mathrm{K})$ & TOA $(\%)$ & $\mathrm{BOA}(\%)$ \\
\hline ABS1 & $4.0 \mu \mathrm{m}$ & $1.0 \mu \mathrm{m}$ & $2.0 \mathrm{~K}$ & $1.7 \mathrm{~K}$ & 12.7 & 8.3 \\
\hline $\mathrm{ABS} 2$ & $6.5 \mu \mathrm{m}$ & $1.0 \mu \mathrm{m}$ & $5.4 \mathrm{~K}$ & $3.0 \mathrm{~K}$ & 25.1 & 7.9 \\
\hline ABS3 & $9.5 \mu \mathrm{m}$ & $1.0 \mu \mathrm{m}$ & $2.2 \mathrm{~K}$ & $3.5 \mathrm{~K}$ & 7.7 & 11.0 \\
\hline ABS4 & $15.0 \mu \mathrm{m}$ & $2.0 \mu \mathrm{m}$ & $7.0 \mathrm{~K}$ & $3.4 \mathrm{~K}$ & 13.8 & 4.0 \\
\hline
\end{tabular}

269 DART accuracy was also analysed in relation to three EO satellite missions (Trishna, Sentinel

270 3, Landsat 8). Table 3 shows the BT difference (DIFF) of their TIR bands, for the USSTD76 15 
atmosphere. Band BTs are computed by inverting Planck function using band mean radiance

272 and band central wavelength. The resulting DART BT DIFFs greatly exceed the satellite sensor

273 sensitivity (Table 3) and also the accuracy usually required for LST applications (i.e., $1 \mathrm{~K}$ ).

274

275 Three already mentioned DART approximations can explain these large differences: (1)

276 Neglect of gas absorption cross-section dependence on pressure and temperature. Indeed, due 277 to the Doppler and Lorentz broadening, absorption cross-sections vary with pressure and 278 temperature, and consequently with altitude; (2) Transmittance computation with Beer's law 279 and band mean optical properties. Indeed, Beer's law is less correct if the absorption cross280 section varies strongly within the spectral bin; (3) Computation of layer thermal emission with 281 the layer mean temperature $T_{j}$, which is only suited for optically thin layers. Therefore, with 282 the objective that DART accuracy meets the requirements of TIR EO satellite missions and 283 LST applications while using Beer's law, two major modelling improvements have been made:

284 (1) account of the vertical variation of gas absorption cross-section, and (2) accurate 285 computation of thermal emission per layer.

Table 3. TOA BT DIFF of initial DART in the TIR bands of three EO satellite missions for the USSTD76 atmosphere. MODTRAN-5 results are the reference.

\begin{tabular}{ccccccc}
\hline Satellite & Launch date & Organization & $\begin{array}{c}\text { Central } \\
\text { wavelength }\end{array}$ & Bandwidth & $\begin{array}{c}\text { Sensitivity } \\
\text { (NeDT) }\end{array}$ & DIFF \\
& & & & & & \\
\hline Trishna & Foreseen & CNES+ISRO & $8.6 \mu \mathrm{m}$ & $0.35 \mu \mathrm{m}$ & $0.3 \mathrm{~K} @ 300 \mathrm{~K}$ & $0.65 \mathrm{~K}$ \\
& $2024-2025$ & & $9.1 \mu \mathrm{m}$ & $0.35 \mu \mathrm{m}$ & $0.3 \mathrm{~K} @ 300 \mathrm{~K}$ & $1.57 \mathrm{~K}$ \\
& & & $10.3 \mu \mathrm{m}$ & $1.0 \mu \mathrm{m}$ & $0.3 \mathrm{~K} @ 300 \mathrm{~K}$ & $2.60 \mathrm{~K}$
\end{tabular}




\begin{tabular}{|c|c|c|c|c|c|c|}
\hline & & & $11.5 \mu \mathrm{m}$ & $1.0 \mu \mathrm{m}$ & 0.3 K@300 K & $1.50 \mathrm{~K}$ \\
\hline \multirow[t]{2}{*}{ Landsat 8} & 2013 & NASA & $10.9 \mu \mathrm{m}$ & $0.6 \mu \mathrm{m}$ & $0.4 \mathrm{~K} @ 300 \mathrm{~K}$ & $1.97 \mathrm{~K}$ \\
\hline & & & $12.0 \mu \mathrm{m}$ & $1.0 \mu \mathrm{m}$ & $0.4 \mathrm{~K} @ 300 \mathrm{~K}$ & $1.73 \mathrm{~K}$ \\
\hline \multirow[t]{3}{*}{ Sentinel 3} & 2016 & ESA & $3.74 \mu \mathrm{m}$ & $0.38 \mu \mathrm{m}$ & $0.08 \mathrm{~K} @ 270 \mathrm{~K}$ & $0.10 \mathrm{~K}$ \\
\hline & & & $10.95 \mu \mathrm{m}$ & $0.9 \mu \mathrm{m}$ & $0.05 \mathrm{~K} @ 270 \mathrm{~K}$ & $1.88 \mathrm{~K}$ \\
\hline & & & $12.0 \mu \mathrm{m}$ & $1.0 \mu \mathrm{m}$ & $0.05 \mathrm{~K} @ 270 \mathrm{~K}$ & $1.73 \mathrm{~K}$ \\
\hline
\end{tabular}

\subsection{Equivalent absorption cross-section database}

\subsubsection{Equivalent absorption cross-section}

As stated above, the initial DART neglects the dependence of gas absorption cross-sections with pressure and temperature. We improved this situation by introducing vertical profiles of equivalent absorption cross-section $\sigma_{m_{i}}^{a}(\lambda, z, \Delta L)$ (Eq. (7)) for five most absorbing gases $\left(\mathrm{H}_{2} \mathrm{O}\right.$,

$\left.297 \mathrm{CO}_{2}, \mathrm{O}_{3}, \mathrm{CH}_{4}, \mathrm{~N}_{2} \mathrm{O}\right) . \sigma_{m_{i}}^{a}$ is the exact band mean absorption cross-section if Beer's law is 298 obeyed.

$$
\sigma_{m_{i}}^{a}(\lambda, z, \Delta L)=\frac{-\ln \left(t_{m_{i}}^{a}(\lambda, z, \Delta L)\right)}{N_{m_{i}}(z) \cdot \Delta L}
$$

300 with $t_{m_{i}}^{a}(\lambda, z, \Delta L)$ the path absorption transmittance of gas $m_{i}$ at altitude $z$, at wavelength $\lambda$, 301 along path segment $\Delta L . N_{m_{i}}(z)$ is the number density of gas $m_{i}$ at altitude $z$. 
To compute $\sigma_{m_{i}}^{a}(\lambda, z, \Delta L)$ (Eq. (7)), MODTRAN $1 \mathrm{~cm}^{-1}$ resolution absorption transmittances $t_{m_{i}}^{a}(\lambda, z, \Delta L)$ were simulated per gas $m_{i}\left(\mathrm{H}_{2} \mathrm{O}, \mathrm{CO}_{2}, \mathrm{O}_{3}, \mathrm{CH}_{4}, \mathrm{~N}_{2} \mathrm{O}\right)$ for identical horizontal paths $\Delta L$ at 36 altitudes $z$ : 26 altitudes from $0 \mathrm{~km}$ up to $25 \mathrm{~km}$ with a step of $1 \mathrm{~km}, 7$ altitudes from $25 \mathrm{~km}$ up to $60 \mathrm{~km}$ with a step of $5 \mathrm{~km}$, and 3 altitudes at $70 \mathrm{~km}, 80 \mathrm{~km}$ and $100 \mathrm{~km}$. The gas number density $N_{m_{i}}(z)$ is derived from MODTRAN tape6 file (Berk et al., 2008).

Figure 5.a and Figure 5.c show the $\mathrm{CO}_{2}$ vertical profiles of $\sigma_{m_{i}}^{a}(\lambda, z, \Delta L)$ from $0 \mathrm{~km}$ altitude up to $25 \mathrm{~km}$ for $13.4 \mu \mathrm{m}$ and up to $15 \mathrm{~km}$ for $13.1 \mu \mathrm{m}$, with $\Delta L=1 \mathrm{~km}, 2 \mathrm{~km}, 5 \mathrm{~km}$ and $10 \mathrm{~km}$. $\sigma_{m_{i}}^{a}(\lambda, z, \Delta L)$ profiles depend on $\Delta L$ if Beer's law is not obeyed (Figure 5.a) and do not depend

312 on $\Delta L$ if Beer's law is obeyed (Figure 5.c). Figure 5.b, d shows that the relative vertical 313 distribution of equivalent absorption cross-section $\sigma_{m_{i}}^{a(*)}(\lambda, z, \Delta L)=\frac{\sigma_{m_{i}}^{a}(\lambda, z, \Delta L)}{\sigma_{m_{i}}^{a}(\lambda, 0, \Delta L)}$ (profiles scaled 314 by $\sigma_{m_{i}}^{a}(\lambda, 0, \Delta L)$ at $\left.\mathrm{z}=0\right)$ is almost independent of $\Delta L$, even if Beer's law is not obeyed, with 315 slightly variations depending on the absorption feature, temperature and pressure. It explains 316 that DART TIR radiance computed with $\sigma_{m_{i}}^{a}(\lambda, z, \Delta L)$ only slightly varies with $\Delta L$. Results in 317 section 5 show that the optimal $\Delta L$ is $7 \mathrm{~km}$. Hereafter, $\sigma_{m_{i}}^{a}(\lambda, z)$ stands for $\sigma_{m_{i}}^{a}(\lambda, z, \Delta L=$ $318 \quad 7 \mathrm{~km})$.

320 Note that $\sigma_{m_{i}}^{a}(\lambda, z)$ is underestimated if the minus logarithm of total transmittance reaches the 321 limit 100 in MODTRAN (i.e., extreme absorbing bands). It can occur at low altitude. Then, the 322 low atmosphere tends to behave as a black body, and the vertical distribution of absorption 323 extinction coefficient within the low atmosphere has little impact on TIR radiance. 

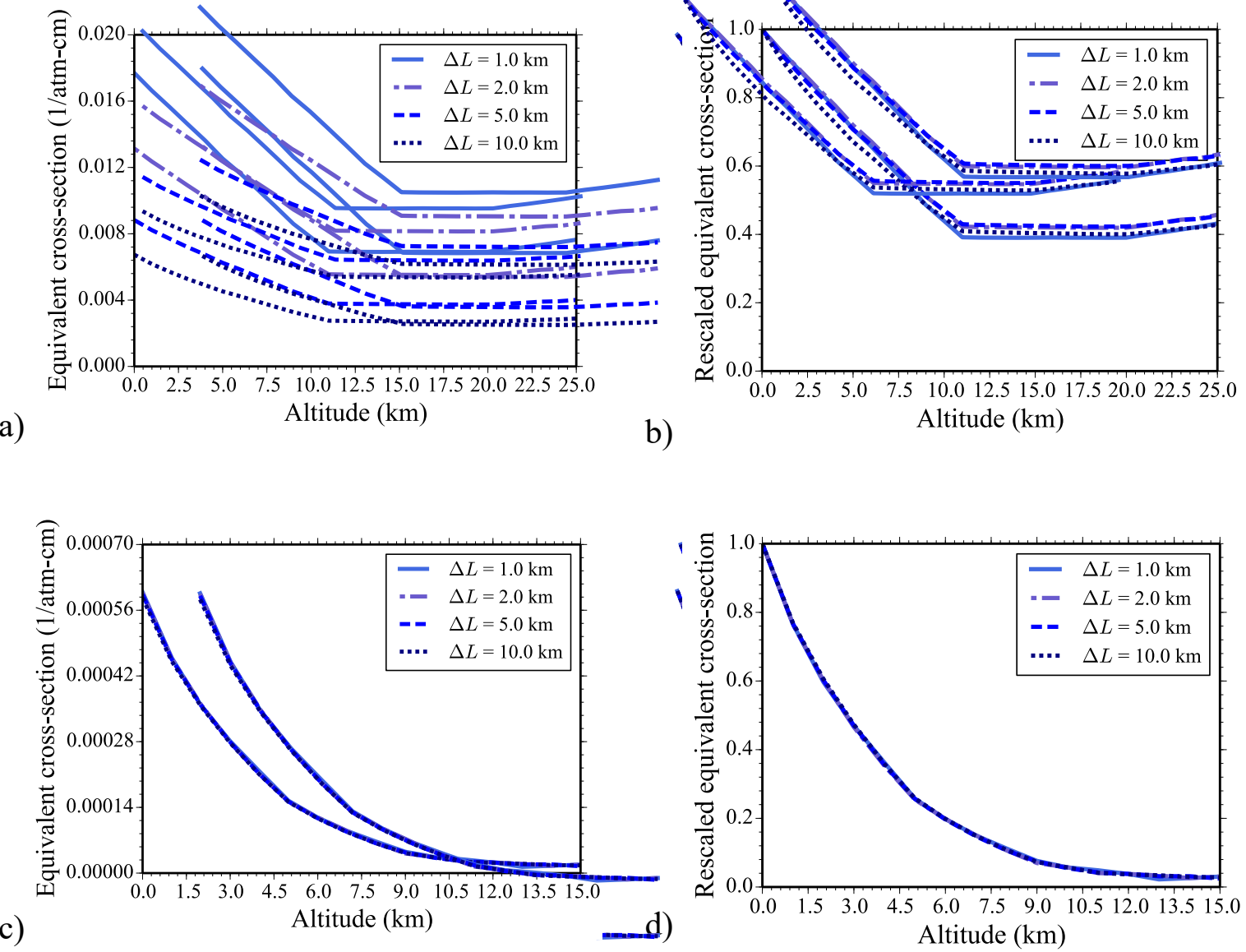

b)

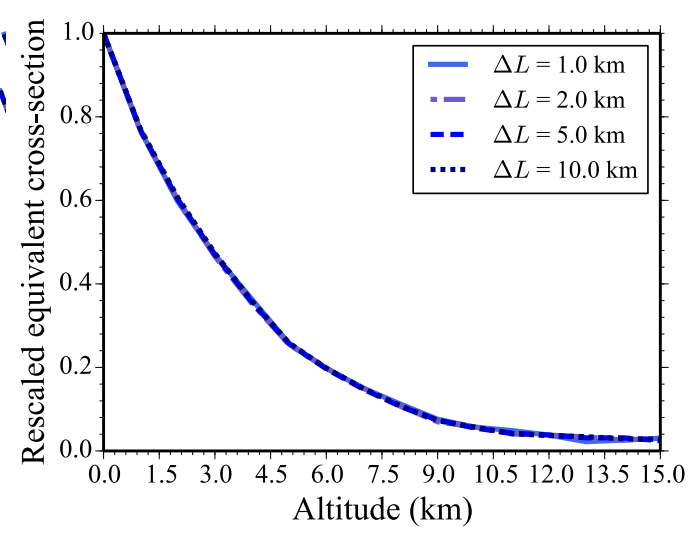

325 Figure 5. $\mathrm{CO}_{2}$ equivalent absorption cross-section $\sigma_{m_{i}}^{a}(\lambda, z, \Delta L)(\mathrm{a}, \mathrm{c})$ and rescaled equivalent absorption cross-section $\sigma_{m_{i}}^{a(*)}(\lambda, z, \Delta L)(\mathrm{b}, \mathrm{d})$ at $13.4 \mu \mathrm{m}(\mathrm{a}, \mathrm{b})$ and $13.1 \mu \mathrm{m}(\mathrm{c}, \mathrm{d})$, in $1 \mathrm{~cm}^{-1}$ spectral bin, for 4 identical horizontal paths ( $\Delta L=1 \mathrm{~km}, 2 \mathrm{~km}, 5 \mathrm{~km}, 10 \mathrm{~km}$ ) at altitudes up to $25 \mathrm{~km}$ for $13.4 \mu \mathrm{m}$ and up to $15 \mathrm{~km}$ for $13.1 \mu \mathrm{m}$, in the USSTD76 atmosphere.

\subsubsection{Creation of SQL database}

332 The equivalent absorption cross-section profiles $\sigma_{m_{i}}^{a}(\lambda, z)$ were computed per gas $m_{i}$ for the

333 six standard atmospheres, from 10 to $3500 \mathrm{~cm}^{-1}$ at $1 \mathrm{~cm}^{-1}$ spectral resolution. To ease data access

334 and management, they were stored in a SQL database per spectral band, per gas $m_{i}$ and per

335 standard atmosphere. Three criteria were used to select the spectral bands of interest: (1)

336 wavelength larger than $3 \mu \mathrm{m}$; (2) absorbing gases; (3) absorbing spectral regions. 
338 The spectral region over $3 \mu \mathrm{m}$ is chosen because the vertical variation of absorption cross339 section impacts much more the TIR region than short waves. Also, since non-absorbing gases 340 have a negligible impact on the TOA / BOA radiance, $\sigma_{m_{i}}^{a}(\lambda, z)$ is stored only for the five most 341 absorbing gases $\left(\mathrm{H}_{2} \mathrm{O}, \mathrm{CO}_{2}, \mathrm{O}_{3}, \mathrm{CH}_{4}, \mathrm{~N}_{2} \mathrm{O}\right)$ and for the absorbing spectral regions of these gases. 342 This trade-off allows one to get accurate TIR RT modelling without increasing too much the 343 DART code complexity and computer time. In non-absorbing bands, MODTRAN absorption 344 transmittance $t_{m_{i}}^{a}(\lambda, z)$ of gas $m_{i}$ at any altitude $z$ along the horizontal path is very close to 1 345 (e.g., 0.99995), which implies that the computed equivalent absorption cross-section is either 346 zero or inaccurate. Therefore, we selected absorbing regions per gas $m_{i}$. For that, a specific 347 altitude $Z_{m_{i}}^{*}$ is defined per gas $m_{i}$ such that under this altitude over $98 \%$ of gas $m_{i}$ is present. $348 Z_{\mathrm{H}_{2} \mathrm{O}}^{*}$ is $8 \mathrm{~km}, Z_{\mathrm{CO}_{2}}^{*}$ is $25 \mathrm{~km}, Z_{\mathrm{O}_{3}}^{*}$ is $40 \mathrm{~km}, Z_{\mathrm{CH}_{4}}^{*}$ and $Z_{\mathrm{N}_{2} \mathrm{O}}^{*}$ are both $23 \mathrm{~km}$. If the sum of 349 equivalent optical depth $-\ln \left(t_{m_{i}}^{a}(\lambda, z)\right)$ for altitude $z>Z_{m_{i}}^{*}$ is not negligible (Eq. (8)), the 350 spectral band is considered as an absorbing band for gas $m_{i}$, and the $\sigma_{m_{i}}^{a}(\lambda, z)$ profile is stored.

$$
\sum_{z>Z_{m_{i}}^{*}}-\ln \left(t_{m_{i}}^{a}(\lambda, z)\right)>\varepsilon
$$

where the threshold $\varepsilon$ corresponds to MODTRAN precision. Any line-of-sight with equivalent optical depth $-\ln \left(t_{m_{i}}^{a}(\lambda, z)\right)$ smaller than $\varepsilon$ is considered as transparent.

\subsubsection{Improved absorption extinction coefficient profile}

357 Eq. (9) indicates how the initial gas absorption extinction coefficient Eq. (2) was improved 358 using the pressure- and temperature-dependent equivalent absorption cross-section. 


$$
\alpha_{j, m_{i}}^{a}(\lambda)= \begin{cases}\frac{-\ln \left(t_{m_{i}}^{a}(\lambda)\right)}{z_{j}-z_{j-1}} \cdot \frac{\int_{z_{j-1}}^{z_{j}} \sigma_{m_{i}}^{a}(\lambda, z) \cdot N_{m_{i}, D B}(z) d z}{\int_{0}^{\infty} \sigma_{m_{i}}^{a}(\lambda, z) \cdot N_{m_{i}, D B}(z) d z}, m_{i}=\mathrm{H}_{2} \mathrm{O}, \mathrm{CO}_{2}, \mathrm{O}_{3}, \mathrm{CH}_{3}, \mathrm{~N}_{2} \mathrm{O} \\ \frac{-\ln \left(t_{m_{i}}^{a}(\lambda)\right)}{z_{j}-z_{j-1}} \cdot \frac{\int_{z_{j-1}}^{z_{j}} \sigma_{m_{i}}^{a}(\lambda) \cdot N_{m_{i}, D B}(z) d z}{\int_{0}^{\infty} \sigma_{m_{i}}^{a}(\lambda) \cdot N_{m_{i}, D B}(z) d z}, \quad m_{i} \neq \mathrm{H}_{2} \mathrm{O}, \mathrm{CO}_{2}, \mathrm{O}_{3}, \mathrm{CH}_{3}, \mathrm{~N}_{2} \mathrm{O}\end{cases}
$$

360 Figure 6 shows vertical profiles of the new absorption extinction coefficients in the USSTD76

361 atmosphere at four spectral bands. Compared to the initial absorption extinction coefficients,

362 they tend to be larger at lower altitudes and smaller at higher altitudes. This is consistent with 363 the stronger absorption behaviour of bottom atmosphere. $\mathrm{O}_{3}$ absorption explains the local 364 maximum $(\approx 20 \mathrm{~km})$ of the initial and new absorption extinction coefficients at $10 \mu \mathrm{m}$.

a)

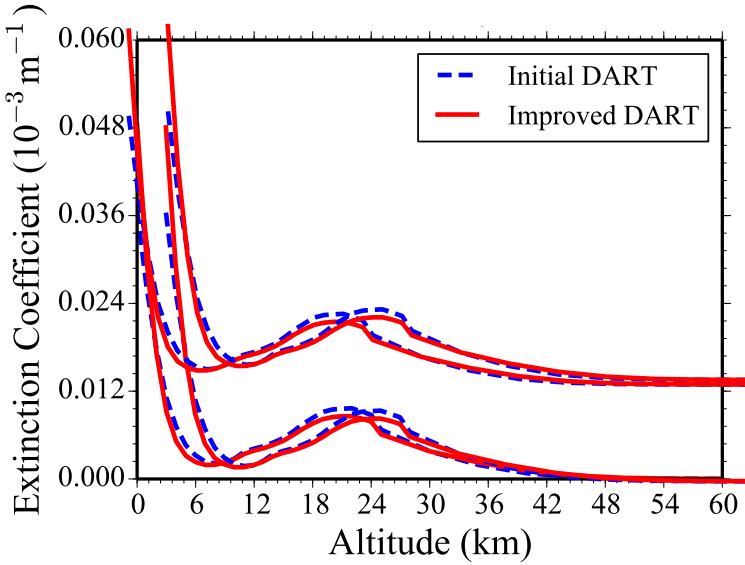

c)

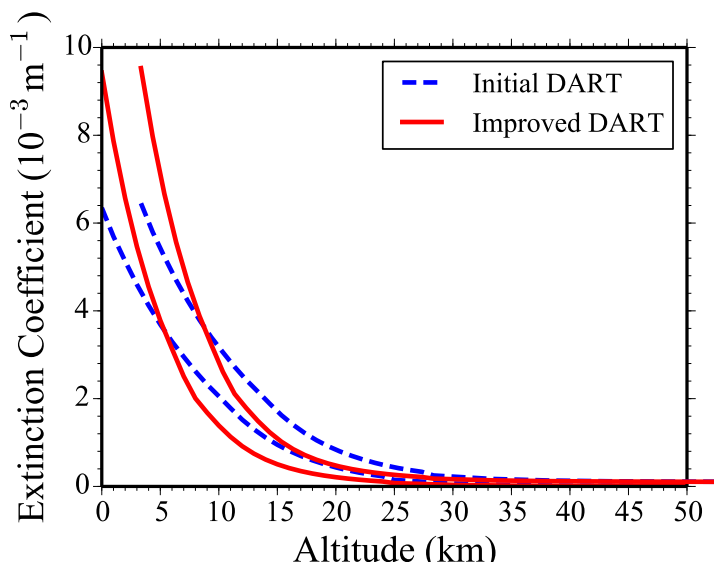

b)

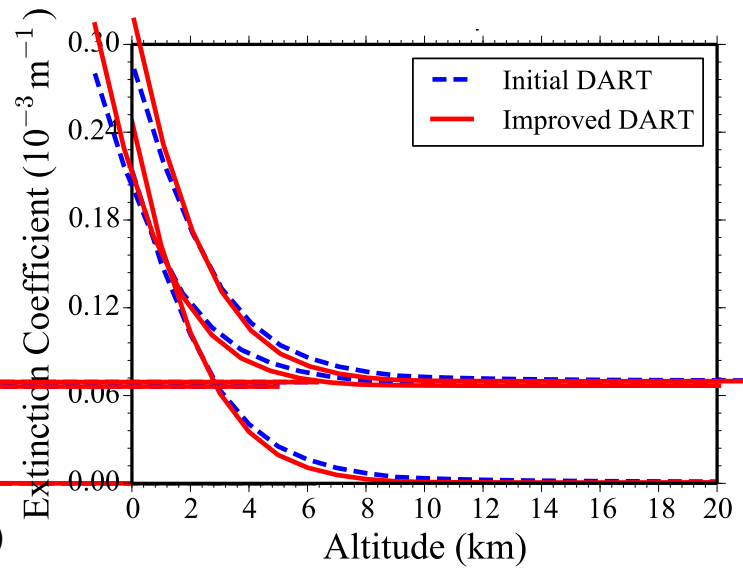

d)

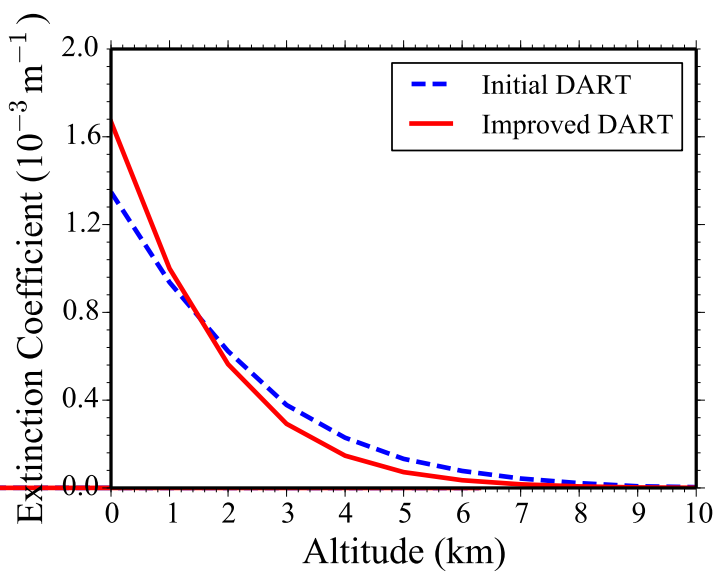

Figure 6. Profiles of DART initial and improved absorption extinction coefficients in the USSTD76 atmosphere. a) $10.0 \mu \mathrm{m}$. b) $13.0 \mu \mathrm{m}$. c) $15.4 \mu \mathrm{m}$. d) $19.6 \mu \mathrm{m}$. Spectral bin is $1 \mathrm{~cm}^{-1}$. 


\subsection{Layer thermal emission}

\subsubsection{A double-layer method}

370

371 The initial thermal emission method (Eq. (5)) is less correct for optically thick atmosphere layer 372 (i.e., $\Delta \tau_{j} \gg 1$ ). For example, if lower boundary temperature is larger than layer mean temperature and if $\Delta \tau_{j} \gg 1$, Eq. (5) tends to underestimate downward thermal vector sources $W_{j}^{\downarrow}(\Omega, \lambda)$. Hence, a double-layer method was first designed (Eq. (10)): half a layer emits with

375 Planck function $L_{B}\left(T_{x}, \lambda\right)$, and the other half emits with Planck function $L_{B}\left(T_{y}, \lambda\right)$.

$$
\begin{aligned}
& W_{j}^{\uparrow}(\Omega, \lambda)=\left(1-\omega_{j}(\lambda)\right) \cdot\left[L_{B}\left(T_{x}, \lambda\right) e^{-\frac{\Delta \tau_{j}}{2 \mu}}+L_{B}\left(T_{y}, \lambda\right)\right]\left[1-e^{-\frac{\Delta \tau_{j}}{2 \mu}}\right] \cdot \mu \cdot \Delta S \cdot \Delta \Omega \\
& W_{j}^{\downarrow}(\Omega, \lambda)=\left(1-\omega_{j}(\lambda)\right) \cdot\left[L_{B}\left(T_{x}, \lambda\right)+L_{B}\left(T_{y}, \lambda\right) e^{-\frac{\Delta \tau_{j}}{2 \mu}}\right]\left[1-e^{-\frac{\Delta \tau_{j}}{2 \mu}}\right] \cdot \mu \cdot \Delta S \cdot \Delta \Omega
\end{aligned}
$$

376

377 In order to get $T_{x}$ and $T_{y}$, four equations associated to schematic configurations must be verified:

1) $\operatorname{Blackbody}\left(\Delta \tau_{j} \gg 1\right.$ and $\left.\omega_{j}(\lambda) \approx 0\right)$

$$
\begin{aligned}
& W_{j}^{\uparrow}(\Omega, \lambda)=L_{B}\left(T_{j}^{U}, \lambda\right) \cdot \mu \cdot \Delta S \cdot \Delta \Omega \\
& W_{j}^{\downarrow}(\Omega, \lambda)=L_{B}\left(T_{j}^{L}, \lambda\right) \cdot \mu \cdot \Delta S \cdot \Delta \Omega
\end{aligned}
$$

379

with $T_{j}^{U}$ and $T_{j}^{L}$ respectively the upper and lower boundary temperature of layer $j$.

381

2) Isothermal $\left(T_{x}=T_{y}=T_{j}\right)$

$$
W_{j}^{\uparrow}(\Omega, \lambda)=\left(1-\omega_{j}(\lambda)\right) \cdot L_{B}\left(T_{j}, \lambda\right) \cdot\left[1-e^{-\frac{\Delta \tau_{j}}{\mu}}\right] \cdot \mu \cdot \Delta S \cdot \Delta \Omega
$$




$$
W_{j}^{\downarrow}(\Omega, \lambda)=\left(1-\omega_{j}(\lambda)\right) \cdot L_{B}\left(T_{j}, \lambda\right) \cdot\left[1-e^{-\frac{\Delta \tau_{j}}{\mu}}\right] \cdot \mu \cdot \Delta S \cdot \Delta \Omega
$$

382

383 Eq. (11) and (12) lead to $T_{x}=T_{j}^{L}$ and $T_{y}=T_{j}^{U}$. The resulting upward and downward vector 384 sources are:

$$
\begin{aligned}
& W_{j}^{\uparrow}(\Omega, \lambda)=\left(1-\omega_{j}(\lambda)\right) \cdot\left[L_{B}\left(T_{j}^{L}, \lambda\right) e^{-\frac{\Delta \tau_{j}}{2 \mu}}+L_{B}\left(T_{j}^{U}, \lambda\right)\right]\left[1-e^{-\frac{\Delta \tau_{j}}{2 \mu}}\right] \cdot \mu \cdot \Delta S \cdot \Delta \Omega \\
& W_{j}^{\downarrow}(\Omega, \lambda)=\left(1-\omega_{j}(\lambda)\right) \cdot\left[L_{B}\left(T_{j}^{L}, \lambda\right)+L_{B}\left(T_{j}^{U}, \lambda\right) e^{-\frac{\Delta \tau_{j}}{2 \mu}}\right]\left[1-e^{-\frac{\Delta \tau_{j}}{2 \mu}}\right] \cdot \mu \cdot \Delta S \cdot \Delta \Omega
\end{aligned}
$$

385

\subsubsection{Thermal emission with virtual sub-layers}

Same as the "linear-in-optical depth" assumption (Clough et al., 1992), the double-layer method

(Eq. (13)) is less correct if the temperature and absorption extinction coefficient gradient within

a layer is large (Wiscombe, 1976). Hence, there is a need to take into account the vertical atmosphere layer $j(j \in[1, J], j=1$ for the bottom layer $)$ is virtually divided into $k_{j}$ sub-layers

$\Delta \tau_{k}(\lambda)=\int_{\tau_{k-1}(\lambda)}^{\tau_{k}(\lambda)} d \tau$ with $k \in\left[1, k_{j}\right]$ (Figure 7). The optical depth of the bottom and top planes

394 of layer $j$ are noted $\tau_{j-1}(\lambda)$ and $\tau_{j}(\lambda)$, respectively, with $\tau_{j}(\lambda)=0$ and $\tau_{j-1}(\lambda)=\Delta \tau_{j}(\lambda)$. The 395 terms $\Delta \tau_{k}(\lambda), \tau_{j}(\lambda), \tau_{j-1}(\lambda), \tau_{k}(\lambda)$ and $\tau_{k-1}(\lambda)$ are computed using analytical expressions of 396 layer optical depth that was already implemented in DART for LiDAR mode $\left(i . e ., \tau_{j}(h, \lambda)=\right.$ 397 $\left.A_{j}(\lambda) \cdot h^{3}+B_{j}(\lambda) \cdot h^{2}+C_{j}(\lambda) \cdot h+D_{j}(\lambda)\right)$. Temperature profile $T_{j}(h)$ is written as a linear 398 approximation: $T_{j}(h)=T_{j}^{L}+\frac{T_{j}^{U}-T_{j}^{L}}{\Delta z_{j}} \cdot h$. 

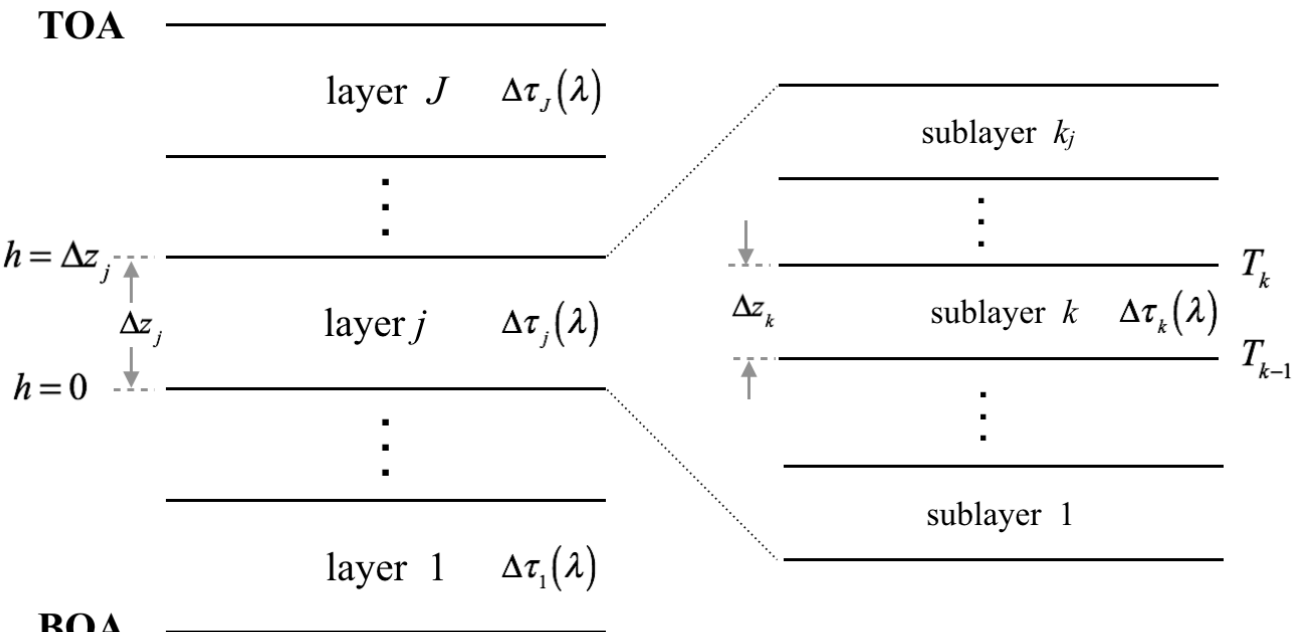
BOA sources $\left(\omega_{j}=0, \mu=1, \Delta S=100 \mathrm{~m}^{2}, \Delta \Omega=0.01 \mathrm{sr}\right)$ of a hot $(\sim 300 \mathrm{~K})$ and cold $(\sim 200 \mathrm{~K})$ atmosphere layer $\left(\Delta z_{j}=1 \mathrm{~km}\right)$ with small $(0.2)$ and large (0.8) transmittance $e^{-\Delta \tau_{j}}$, for $k_{j}$ from 1 to 10 , from

$4113 \mu \mathrm{m}$ to $20 \mu \mathrm{m}$. Bottom layer parameters are: $T_{j}^{L}=T^{L}, \alpha_{j}^{e}(0, \lambda)=\alpha_{0}^{e}, \tau_{j}(0, \lambda)=\Delta \tau_{j}$; upper layer 412 parameters are: $T_{j}^{U}=T^{U}, \alpha_{j}^{e}\left(\Delta z_{l}, \lambda\right)=\alpha_{0}^{e} \cdot e^{-\frac{\Delta z_{j}}{H}}, \tau_{j}\left(\Delta z_{j}, \lambda\right)=0$, with $H=8.4 \mathrm{~km}$ the usual scale 
413 height of major gases. Sub-layer boundary temperature and optical depth are computed as

414 described at the beginning of this section. Here, the reference is the vector source $W_{\text {ref }}^{\uparrow}(\Omega, \lambda)$

415 computed with $k_{j}=1000$. Figure 8 shows that MARE for $k_{j}=1$ can reach $7 \%$ and that $k_{j}=5$

416 gives accurate source vectors for most atmospheric conditions. Note that for atmospheric

417 conditions less extreme than these in this test, the double-layer method usually gives better 418 results.

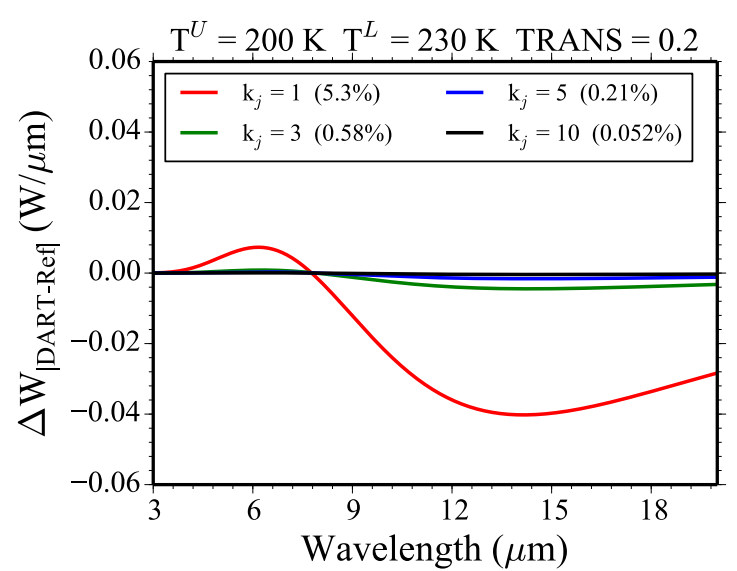

a)

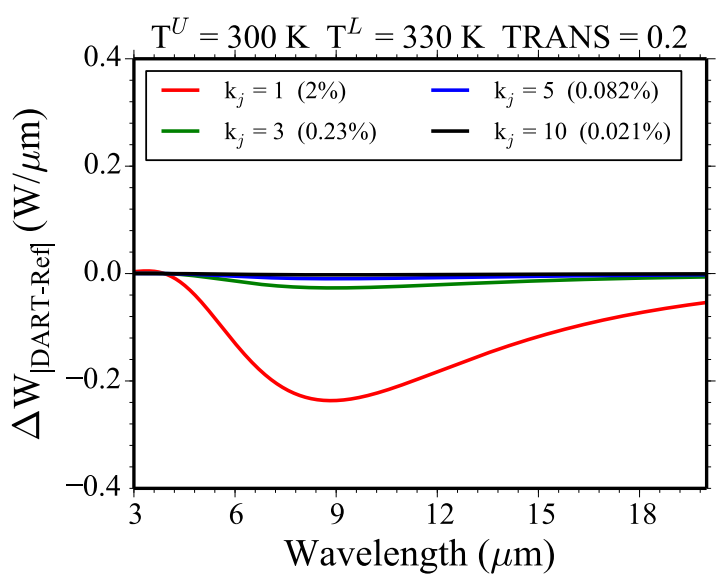

c)

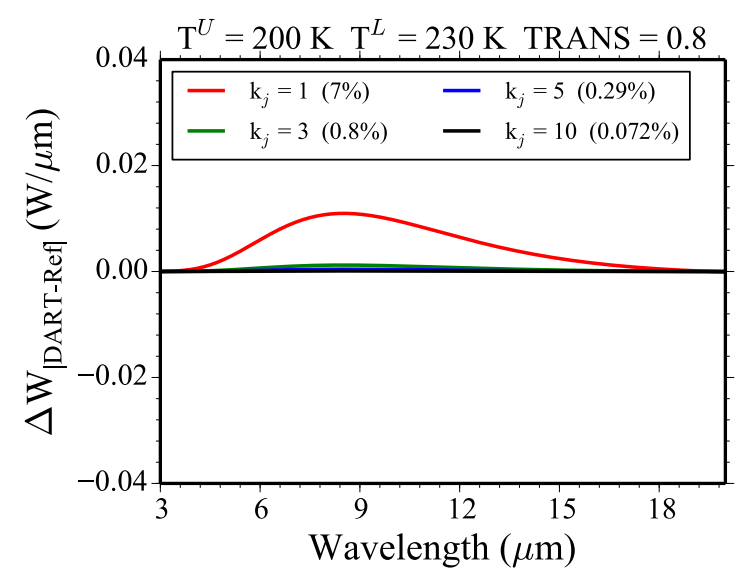

b)

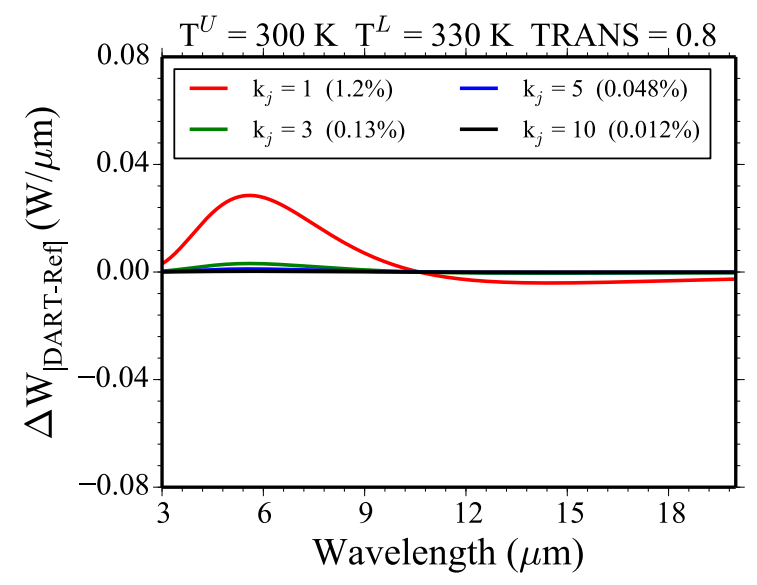

d)

Figure 8. Difference of DART double-layer upward vector source compared with the reference, for various numbers of sub-layers. $T^{U}$ and $T^{L}$ are respectively the upper and lower boundary temperatures. TRANS represents the layer transmittance. MARE is marked in the legend. 


\section{Results and discussion}

425

426

427 428

430

431

Table 4. Average MAE of TOA and BOA BT over $[3.5 \mu \mathrm{m}, 20 \mu \mathrm{m}]$ region of six standard atmospheres,

\begin{tabular}{ccccccc}
\hline$\Delta L$ & $4 \mathrm{~km}$ & $5 \mathrm{~km}$ & $6 \mathrm{~km}$ & $7 \mathrm{~km}$ & $8 \mathrm{~km}$ & $9 \mathrm{~km}$ \\
\hline AVG BT & 0.7489 & 0.7157 & 0.6828 & 0.6728 & 0.6731 & 0.6805 \\
MAE (K) & & & & & &
\end{tabular}

\subsubsection{Optimal path length $\Delta L$}

Section 4 stresses that the path length $\Delta L$ used to compute the equivalent absorption crosssection can slightly impact the TIR radiance. Therefore, we investigated 10 equivalent absorption cross-section databases with $\Delta L$ from $1 \mathrm{~km}$ to $10 \mathrm{~km}$, with $1 \mathrm{~km}$ interval, in order to determine the optimal $\Delta L$. TOA and BOA radiance spectra over [3.5 $\mu \mathrm{m}, 20 \mu \mathrm{m}]$ were simulated with these databases for the six standard atmospheres. Table 4 shows the corresponding average MAE of TOA and BOA BT of six standard atmospheres for the equivalent absorption cross-section databases with $\Delta L$ from $4 \mathrm{~km}$ to $9 \mathrm{~km}$. We chose $\Delta L=7 \mathrm{~km}$ since it gives the best results compared to MODTRAN-5. Note that $\Delta L=6 \mathrm{~km}, 8 \mathrm{~km}$, and 9 $\mathrm{km}$ can also give good results with average BT MAE less than $0.7 \mathrm{~K}$. Hereafter, all the DART simulations use the " $\Delta L=7 \mathrm{~km}$ " absorption cross-section database.

with path lengths $\Delta L$ from $4 \mathrm{~km}$ to $9 \mathrm{~km}$. MODTRAN-5 results are the reference. 


\subsubsection{Improved TOA and BOA thermal radiance}

447 Figure 9 shows the DART and MODTRAN-5 TIR radiance spectra of the USSTD76, 448 MIDDLATSUM, TROPICAL and SUBARCWIN atmospheres, with the same configurations 449 as in Figure 4. Table 5 gives the MAE of TIR BT and MARE of TIR radiance of the improved 450 DART and MODTRAN-5 for the six standard atmospheres over [3.5 $\mu \mathrm{m}, 20 \mu \mathrm{m}$ ]. Compared 451 to initial results in section 3, the average TIR radiance MARE of the six standard atmospheres 452 is reduced from $12.7 \%$ to $3.0 \%$ at TOA level, and from $6.7 \%$ to $2.3 \%$ at BOA level. Similarly, 453 the average BT MAE is reduced from $3.1 \mathrm{~K}$ to $0.71 \mathrm{~K}$ at TOA level and from $2.1 \mathrm{~K}$ to $0.64 \mathrm{~K}$ 454 at BOA level. Table 6 indicates that the largest improvements occur in TIR absorbing regions 455 (e.g., $3.5-4.5 \mu \mathrm{m}, 6-7 \mu \mathrm{m}, 9-10 \mu \mathrm{m}, 14-16 \mu \mathrm{m})$. For example, with the USSTD76 atmosphere, 456 the BT MAE in $[14 \mu \mathrm{m}, 16 \mu \mathrm{m}]$ region is reduced from $7.0 \mathrm{~K}$ to $0.9 \mathrm{~K}$ at TOA level and from $457 \quad 3.4 \mathrm{~K}$ to $0.7 \mathrm{~K}$ at BOA level.

459 The BT DIFF "improved DART vs. MODTRAN-5" for the TIR bands of the aforementioned 460 EO satellite missions (Table 7) stresses that current DART accuracy meets the sensitivity of 461 these three satellite missions. For example, for the $12 \mu \mathrm{m}$ band of Landsat 8 , the DIFF is reduced 462 from $1.73 \mathrm{~K}$ to $0.025 \mathrm{~K}$, which is much smaller than the sensor sensitivity $(0.4 \mathrm{~K}$ at $300 \mathrm{~K})$. 


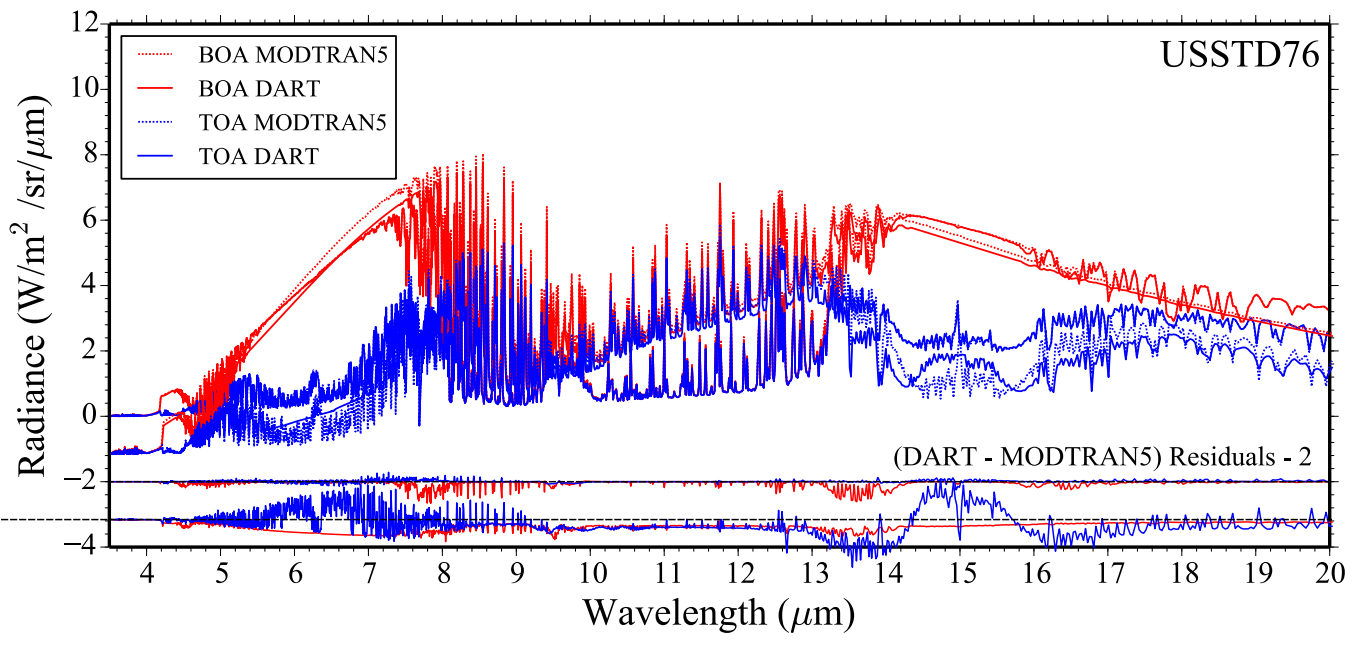

a)

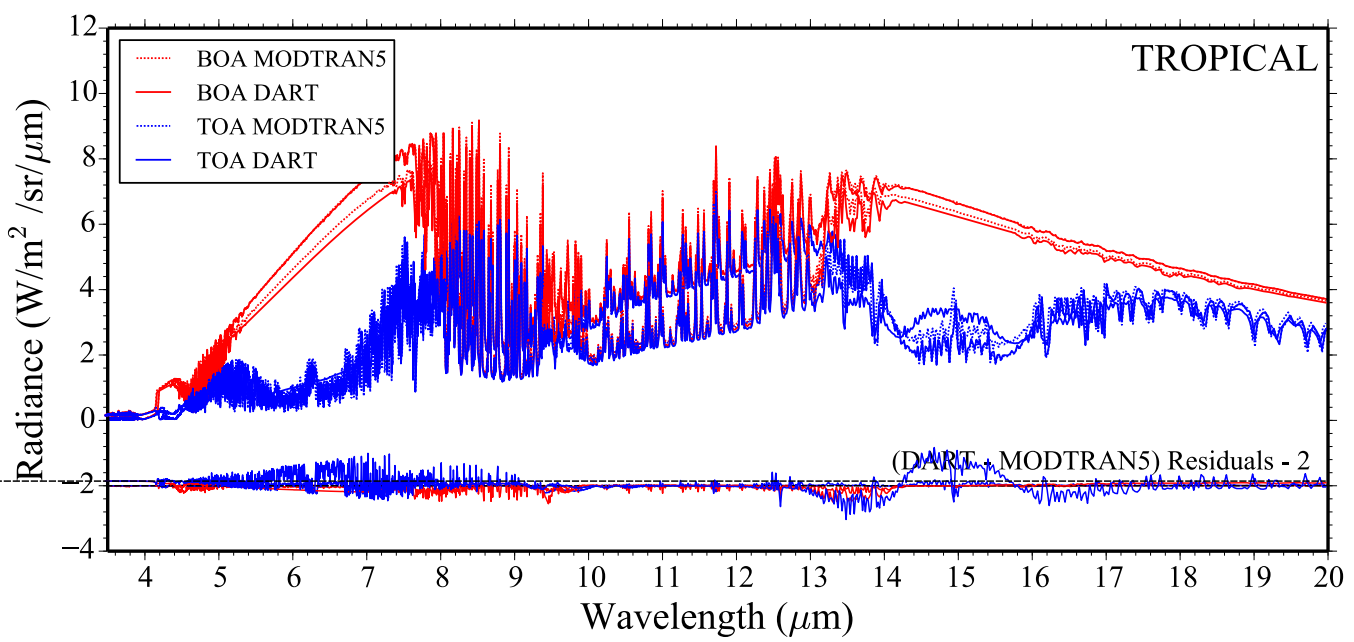

c)

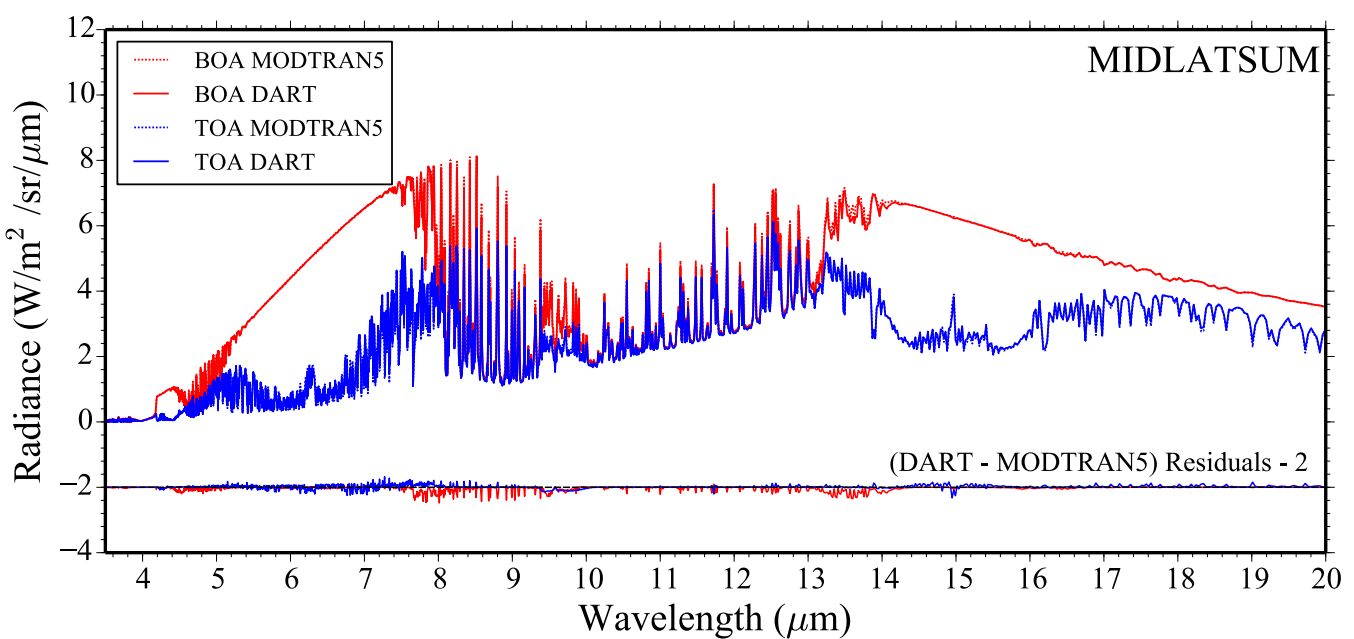


d)

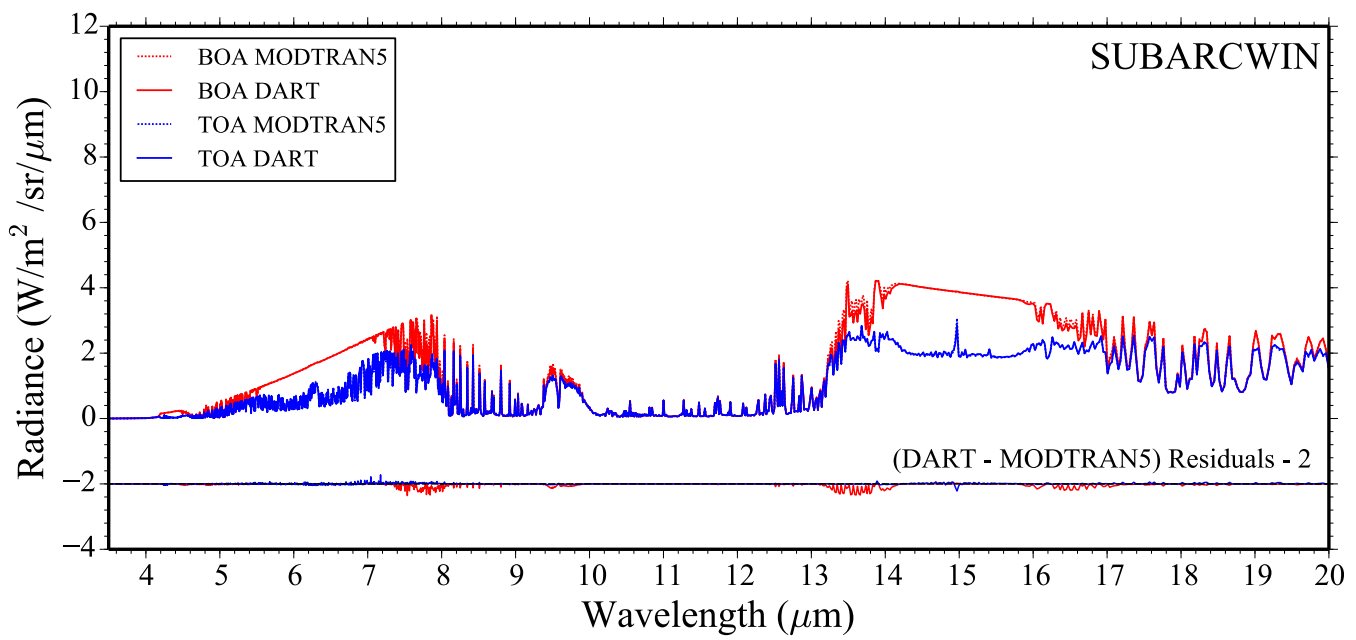

464

465

466

467

468

469

470

Figure 9. Improved DART and MODTRAN-5 TOA / BOA TIR radiance in [3.5 $\mu \mathrm{m}, 20 \mu \mathrm{m}]$ region for USSTD76 (a), TROPICAL (b), MIDLATSUM (c) and SUBARCWIN (d) atmospheres. $1 \mathrm{~cm}^{-1}$ spectral resolution. DART and MODTRAN-5 configurations are detailed in section 3.

Table 5. TOA and BOA BT MAE and radiance MARE of improved DART in [3.5 $\mu \mathrm{m}, 20 \mu \mathrm{m}$ ] region for six atmospheres. MODTRAN-5 results are the reference.

\begin{tabular}{ccccc}
\hline Atmosphere & TOA MAE & BOA MAE & TOA MARE & BOA MARE \\
\hline USSTD76 & $0.68 \mathrm{~K}$ & $0.83 \mathrm{~K}$ & $3.0 \%$ & $2.8 \%$ \\
TROPICAL & $0.97 \mathrm{~K}$ & $0.58 \mathrm{~K}$ & $3.8 \%$ & $2.0 \%$ \\
MIDLATSUM & $0.88 \mathrm{~K}$ & $0.57 \mathrm{~K}$ & $3.5 \%$ & $2.0 \%$ \\
MIDLATWIN & $0.55 \mathrm{~K}$ & $0.63 \mathrm{~K}$ & $2.5 \%$ & $2.3 \%$ \\
SUMARCSUM & $0.75 \mathrm{~K}$ & $0.66 \mathrm{~K}$ & $3.1 \%$ & $2.3 \%$ \\
SUMARCWIN & $0.44 \mathrm{~K}$ & $0.54 \mathrm{~K}$ & $2.2 \%$ & $2.2 \%$ \\
AVERAGE & $0.71 \mathrm{~K}$ & $0.64 \mathrm{~K}$ & $3.0 \%$ & $2.3 \%$ \\
& & & & \\
\hline
\end{tabular}


Table 6. TOA and BOA BT MAE and radiance MARE of improved DART in three TIR absorbing bands for the USSTD76 atmosphere. MODTRAN-5 results are the reference.

\begin{tabular}{ccccccc}
\hline $\begin{array}{c}\text { Absorption } \\
\text { bands }\end{array}$ & $\begin{array}{c}\text { Central } \\
\text { wavelength }\end{array}$ & Bandwidth & TOA MAE & BOA MAE & TOA MARE BOA MARE \\
\hline ABS1 & $4.0 \mu \mathrm{m}$ & $1.0 \mu \mathrm{m}$ & $0.7 \mathrm{~K}$ & $0.7 \mathrm{~K}$ & $4.0 \%$ & $3.5 \%$ \\
$\mathrm{ABS} 2$ & $6.5 \mu \mathrm{m}$ & $1.0 \mu \mathrm{m}$ & $1.4 \mathrm{~K}$ & $0.1 \mathrm{~K}$ & $5.5 \%$ & $0.3 \%$ \\
$\mathrm{ABS3}$ & $9.5 \mu \mathrm{m}$ & $1.0 \mu \mathrm{m}$ & $0.6 \mathrm{~K}$ & $1.0 \mathrm{~K}$ & $1.8 \%$ & $2.9 \%$ \\
$\mathrm{ABS} 4$ & $15.0 \mu \mathrm{m}$ & $2.0 \mu \mathrm{m}$ & $0.9 \mathrm{~K}$ & $0.7 \mathrm{~K}$ & $1.7 \%$ & $0.9 \%$ \\
\hline
\end{tabular}

474

475 Table 7. TOA BT DIFF improved DART in the TIR bands of three EO satellite missions for the 476 USSTD76 atmosphere. MODTRAN-5 results are the reference.

\begin{tabular}{|c|c|c|c|c|c|c|}
\hline Satellite & Launch date & Organization & $\begin{array}{c}\text { Central } \\
\text { wavelength }\end{array}$ & Bandwidth & $\begin{array}{l}\text { Sensitivity } \\
(\mathrm{NeDT})\end{array}$ & $\begin{array}{c}\text { Improved } \\
\text { DIFF }\end{array}$ \\
\hline \multirow[t]{4}{*}{ Trishna } & foreseen & CNES+ISRO & $8.6 \mu \mathrm{m}$ & $0.35 \mu \mathrm{m}$ & $0.3 \mathrm{~K} @ 300 \mathrm{~K}$ & $0.153 \mathrm{~K}$ \\
\hline & $2024-2025$ & & $9.1 \mu \mathrm{m}$ & $0.35 \mu \mathrm{m}$ & $0.3 \mathrm{~K} @ 300 \mathrm{~K}$ & $0.049 \mathrm{~K}$ \\
\hline & & & $10.3 \mu \mathrm{m}$ & $1.0 \mu \mathrm{m}$ & $0.3 \mathrm{~K} @ 300 \mathrm{~K}$ & $0.197 \mathrm{~K}$ \\
\hline & & & $11.5 \mu \mathrm{m}$ & $1.0 \mu \mathrm{m}$ & $0.3 \mathrm{~K} @ 300 \mathrm{~K}$ & $0.005 \mathrm{~K}$ \\
\hline \multirow[t]{2}{*}{ Landsat 8} & 2013 & NASA & $10.9 \mu \mathrm{m}$ & $0.6 \mu \mathrm{m}$ & $0.4 \mathrm{~K} @ 300 \mathrm{~K}$ & $0.009 \mathrm{~K}$ \\
\hline & & & $12.0 \mu \mathrm{m}$ & $1.0 \mu \mathrm{m}$ & $0.4 \mathrm{~K} @ 300 \mathrm{~K}$ & $0.025 \mathrm{~K}$ \\
\hline \multirow[t]{3}{*}{ Sentinel 3} & 2016 & ESA & $3.74 \mu \mathrm{m}$ & $0.38 \mu \mathrm{m}$ & $0.08 \mathrm{~K} @ 270 \mathrm{~K}$ & $0.022 \mathrm{~K}$ \\
\hline & & & $10.95 \mu \mathrm{m}$ & $0.9 \mu \mathrm{m}$ & $0.05 \mathrm{~K} @ 270 \mathrm{~K}$ & $0.011 \mathrm{~K}$ \\
\hline & & & $12.0 \mu \mathrm{m}$ & $1.0 \mu \mathrm{m}$ & $0.05 \mathrm{~K} @ 270 \mathrm{~K}$ & $0.025 \mathrm{~K}$ \\
\hline
\end{tabular}


478 The accuracy of the improved DART was successfully tested for oblique viewing directions.

479 Table 8 summarizes the MAE of TOA and BOA BT for viewing directions with $\theta$ from $0^{\circ}$ to $48060^{\circ}$. Figure 10 shows TOA / BOA TIR radiance spectra for viewing zenith angles $\theta=30^{\circ}$ and $481 \theta=60^{\circ}$, for the USSTD76 atmosphere. Along viewing zenith angle $\theta=30^{\circ}$, the BT MAE is $4820.74 \mathrm{~K}$ at TOA level and $0.70 \mathrm{~K}$ at BOA level, along viewing zenith angle $\theta=60^{\circ}$, the BT MAE 483 is $1.36 \mathrm{~K}$ at TOA level and $0.52 \mathrm{~K}$ at BOA level.

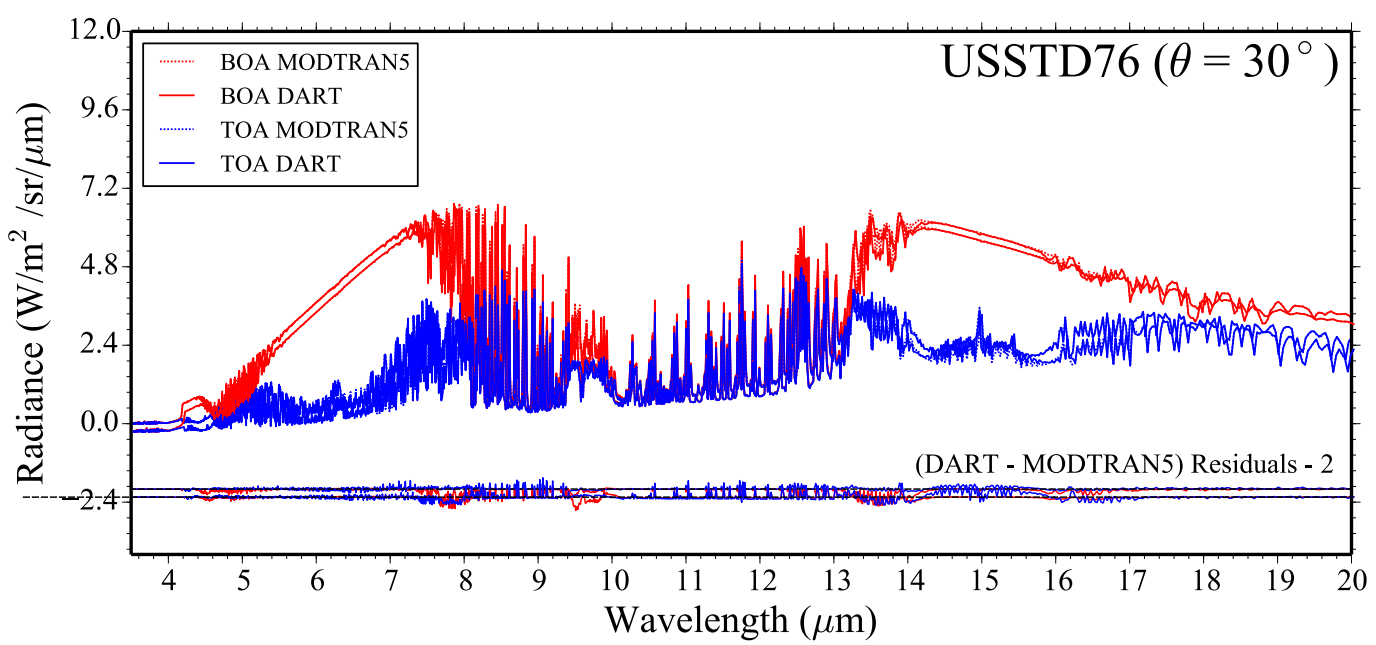

a)

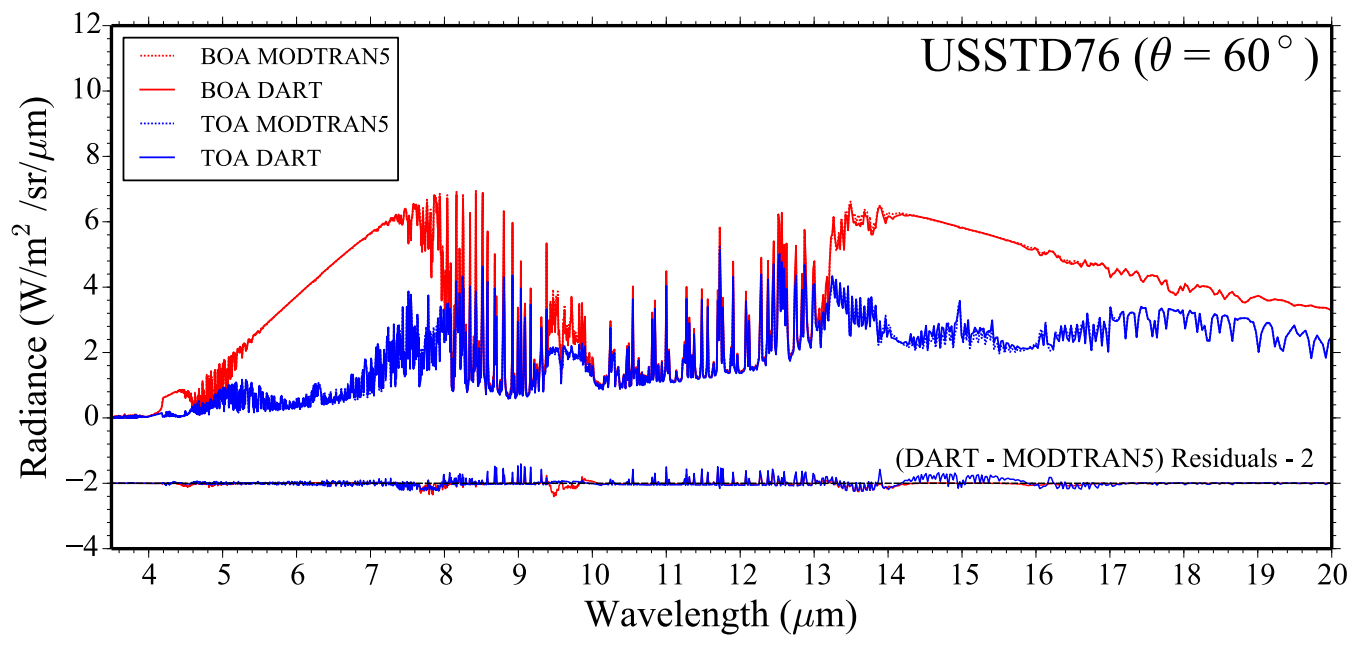

Figure 10. Improved DART and MODTRAN-5 TOA / BOA TIR radiance in [3.5 $\mu \mathrm{m}, 20 \mu \mathrm{m}]$ region for the USSTD76 atmosphere. Viewing zenith angle $\theta=30^{\circ}$ (a) and $\theta=60^{\circ}(\mathrm{b})$. 


\begin{tabular}{cccccccc}
\hline$\theta$ & $0^{\circ}$ & $10^{\circ}$ & $20^{\circ}$ & $30^{\circ}$ & $40^{\circ}$ & $50^{\circ}$ & $60^{\circ}$ \\
\hline TOA BT & 0.68 & 0.71 & 0.71 & 0.74 & 0.82 & 1.0 & 1.36 \\
MAE (K) & & & & & & & \\
BOA BT & 0.83 & 0.83 & 0.78 & 0.70 & 0.60 & 0.53 & 0.52 \\
MAE (K) & & & & & & & \\
\hline
\end{tabular}

Table 8. Average MAE of TOA and BOA BT of the USSTD76 atmosphere over [3.5 $\mu \mathrm{m}, 20 \mu \mathrm{m}$ ] region, with viewing directions $\theta$ from $0^{\circ}$ to $60^{\circ}$. MODTRAN-5 results are the reference.
489

\subsection{Validation}

DART improvement was validated by comparing DART and MODTRAN-5 simulations with atmosphere profiles from ECMWF (European Centre for Medium-range Weather Forecasts) reanalysis dataset: ERA-Interim (https://apps.ecmwf.int/datasets/). These profiles include the pressure, temperature, specific humidity (mass of water vapour per kilogram of moist air, nearly equal to mass mixing ratio within a few percent) and $\mathrm{O}_{3}$ mass mixing ratio (mass of ozone per kilogram of dry air) at 60 ECMWF model levels (https://www.ecmwf.int/en/forecasts/documentation-and-support/60-model-levels) as well as the surface albedo, skin temperature over France $\left(49^{\circ} \mathrm{N},-1^{\circ} \mathrm{W}, 44^{\circ} \mathrm{S}, 7^{\circ} \mathrm{E}\right)$ and the Mediterranean Sea $\left(37^{\circ} \mathrm{N}, 12^{\circ} \mathrm{W}, 34^{\circ} \mathrm{S}, 26^{\circ} \mathrm{E}\right)$ from $01 / 06 / 2018$ to $31 / 08 / 2018$. These data were averaged over time and space and the vertical profiles were interpolated into 37 altitude levels ( $1 \mathrm{~km}$ interval from 0 to $25 \mathrm{~km}$, and $5 \mathrm{~km}$ interval from 30 to $80 \mathrm{~km}$ ) that are configured in both DART and MODTRAN-5. The number density profile $N_{m_{i}}(z)$ of other gases $\left(\mathrm{N}_{2}, \mathrm{CO}_{2}, \mathrm{CO}\right.$, $\mathrm{CH}_{4}, \mathrm{~N}_{2} \mathrm{O}, \mathrm{O}_{2}, \mathrm{NH}_{3}, \mathrm{NO}, \mathrm{NO}_{2}, \mathrm{SO}_{2}, \mathrm{HNO}_{3}, \mathrm{CFC}_{12}, \mathrm{CFC}_{13}, \mathrm{CFC}_{14}, \mathrm{CFC}_{22}, \mathrm{CFC}_{113}, \mathrm{CFC}_{114}$, $\left.\mathrm{CFC}_{115}, \mathrm{CLONO}_{2}, \mathrm{HNO}_{4}, \mathrm{CHCL}_{2} \mathrm{~F}, \mathrm{CCL}_{4}, \mathrm{~N}_{2} \mathrm{O}_{5}\right)$ and the relative density profile $\rho_{m}^{s}(z)$ of 
scattering gases are adjusted by MODTRAN-5 based on the MIDLATSUM atmosphere and

507 the actual pressure and temperature profile from ERA-Interim dataset.

509 Figure 11.a shows the pressure, temperature, $\mathrm{H}_{2} \mathrm{O}, \mathrm{O}_{3}$ and $\mathrm{CO}_{2}$ number density profiles for three 510 summer atmospheres in the mid-latitude region: France, Mediterranean Sea, and the standard 511 MIDLATSUM atmosphere. Figure 11.b shows the corresponding maximum difference values 512 of profiles per altitude level. Temperature varies up to $10 \mathrm{~K}$ at around $11 \mathrm{~km}$, water vapour 513 mass varies up to $38 \%$ at the Earth surface and $\mathrm{O}_{3}$ mass varies up to $40 \%$ at around $16 \mathrm{~km}$. The 514 averaged continental surface albedo and skin temperature of France are 0.132 and $292 \mathrm{~K}$, 515 respectively. For the Mediterranean Sea, they are 0.07 and 296 K, respectively.
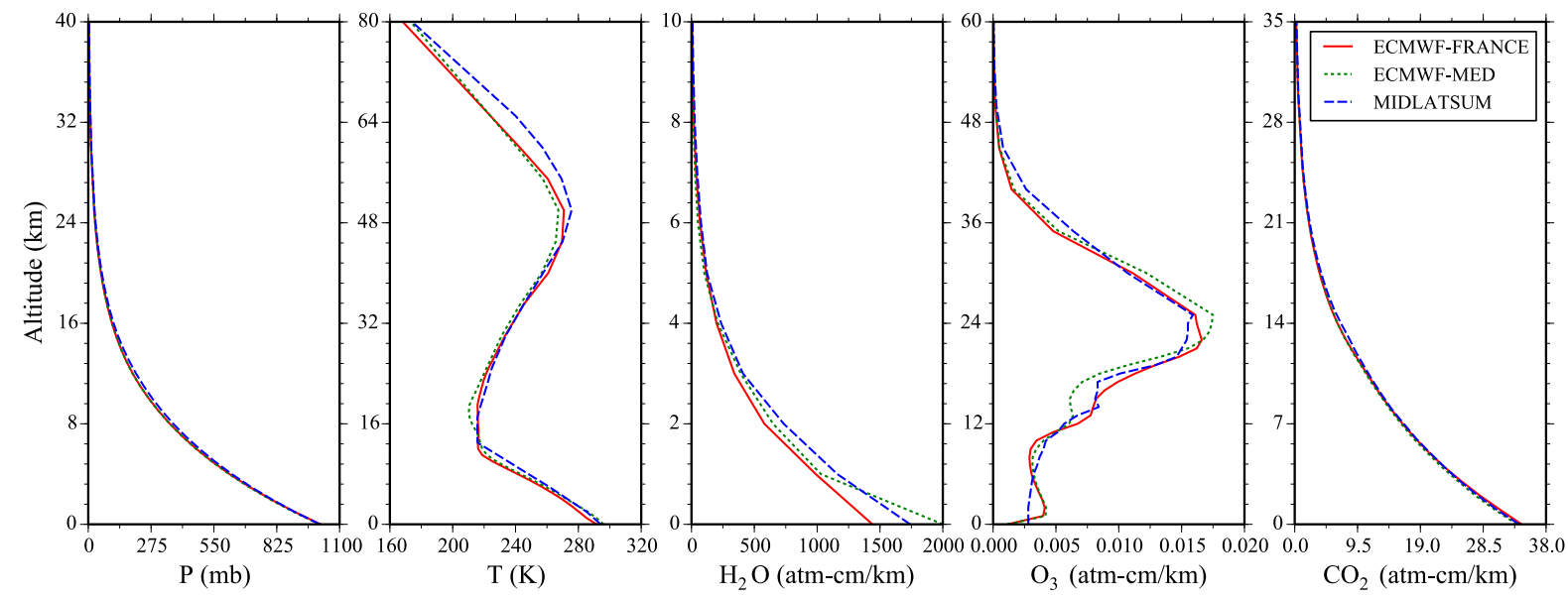

a)
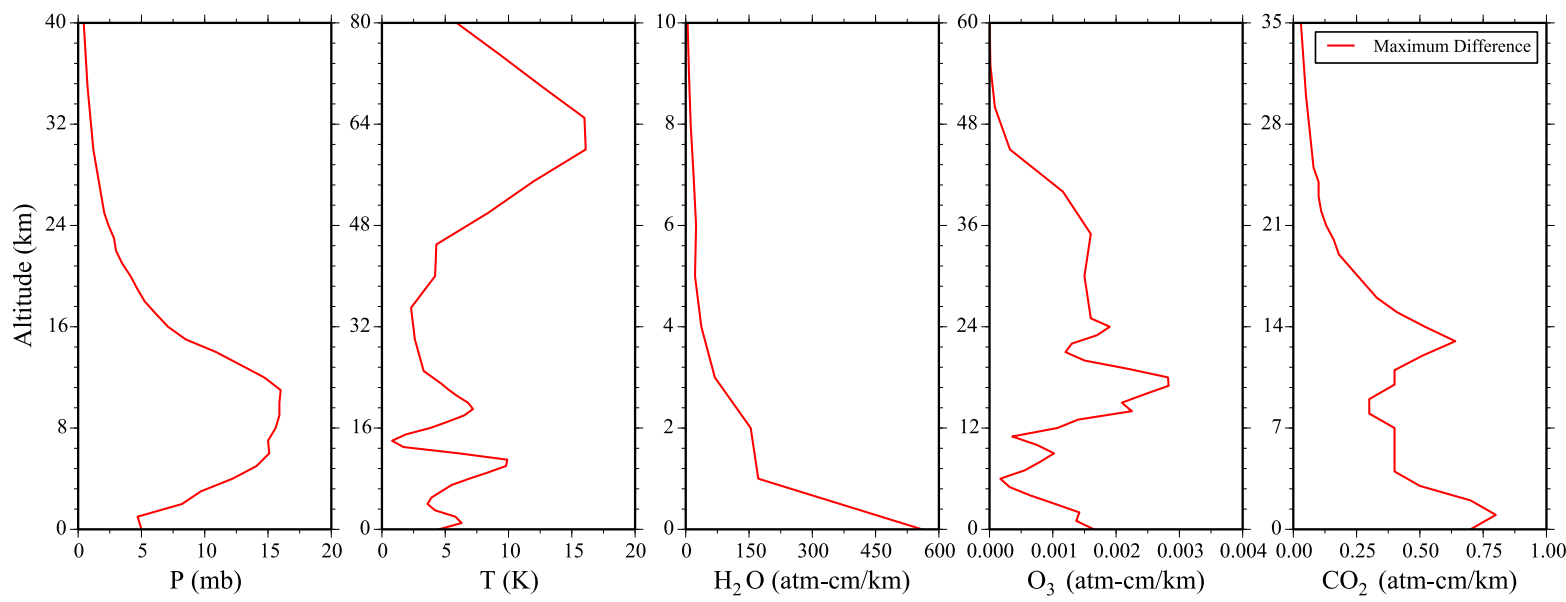
Figure 11. a) Vertical profiles of pressure $(\mathrm{mb})$, temperature $(\mathrm{K})$, and $\mathrm{H}_{2} \mathrm{O}, \mathrm{O}_{3}$ and $\mathrm{CO}_{2}$ number densities $(\mathrm{atm}-\mathrm{cm} / \mathrm{km})$ for three summer atmospheres: France, Mediterranean Sea and

DART and MODTRAN-5 were run in full radiance mode (simulation with solar radiation and thermal emission), with the same sun viewing angle $\left(\theta_{\text {sun }}=30^{\circ}, \varphi_{\text {sun }}=225^{\circ}\right)$, surface parameters, discrete altitude levels, pressure, temperature profiles and gas number density profiles. Eq. (15) indicates how the gas optical depth was adjusted in DART using the userdefined density profiles $N_{m_{i}}(z)$ and $\rho_{m}^{s}(z)$.

$$
\begin{aligned}
& \tau_{m_{i}}^{a}(\lambda)=\left\{\begin{array}{l}
-\ln \left(t_{m_{i}, D B}^{a}(\lambda)\right) \cdot \frac{\int_{0}^{\infty} \sigma_{m_{i}, D B}^{a}(\lambda, z) \cdot N_{m_{i}}(z) d z}{\int_{0}^{\infty} \sigma_{m_{i}, D B}^{a}(\lambda, z) \cdot N_{m_{i}, D B}(z) d z}, m_{i}=\mathrm{H}_{2} \mathrm{O}, \mathrm{CO}_{2}, \mathrm{O}_{3}, \mathrm{CH}_{4}, \mathrm{~N}_{2} \mathrm{O} \\
-\ln \left(t_{m_{i}, D B}^{a}(\lambda)\right) \cdot \frac{\int_{0}^{\infty} \sigma_{m_{i}}^{a}(\lambda) \cdot N_{m_{i}}(z) d z}{\int_{0}^{\infty} \sigma_{m_{i}}^{a}(\lambda) \cdot N_{m_{i}, D B}(z) d z}, \quad m_{i} \neq \mathrm{H}_{2} \mathrm{O}, \mathrm{CO}_{2}, \mathrm{O}_{3}, \mathrm{CH}_{4}, \mathrm{~N}_{2} \mathrm{O}
\end{array}\right. \\
& \tau^{s}(\lambda)=-\ln \left(t_{m, D B}^{s}(\lambda)\right) \cdot \frac{\int_{0}^{\infty} \rho_{m}^{s}(z) d z}{\int_{0}^{\infty} \rho_{m, D B}^{s}(z) d z}
\end{aligned}
$$

Note that $m_{i}$ represents 13 gases $\left(\mathrm{H}_{2} \mathrm{O}, \mathrm{O}_{3}, \mathrm{~N}_{2}, \mathrm{CO}_{2}, \mathrm{CO}, \mathrm{CH}_{4}, \mathrm{~N}_{2} \mathrm{O}, \mathrm{O}_{2}, \mathrm{NH}_{3}, \mathrm{NO}, \mathrm{NO}_{2}, \mathrm{SO}_{2}\right.$,

$\left.\mathrm{HNO}_{3}\right)$ and the sum of other minor gases $\left(\mathrm{CFC}_{12}, \mathrm{CFC}_{13}, \mathrm{CFC}_{14}, \mathrm{CFC}_{22}, \mathrm{CFC}_{113}, \mathrm{CFC}_{114}\right.$, $\left.\mathrm{CFC}_{115}, \mathrm{CLONO}_{2}, \mathrm{HNO}_{4}, \mathrm{CHCL}_{2} \mathrm{~F}, \mathrm{CCL}_{4}, \mathrm{~N}_{2} \mathrm{O}_{5}\right)$.

Figure 12 shows the MODTRAN-5 and initial and improved DART TOA nadir radiance spectra over France and Mediterranean Sea. BT MAE is reduced from 3.6 K to $1.0 \mathrm{~K}$ for France summer 532 atmosphere, and from $3.7 \mathrm{~K}$ to $1.0 \mathrm{~K}$ for the Mediterranean Sea summer atmosphere. We can 533 note that the residuals between improved DART and MODTRAN-5 over [3.5 $\mu \mathrm{m}, 5.0 \mu \mathrm{m}]$ 534 region where solar radiation contributes most to TOA radiance is relatively small $(<0.1$ $535 \mathrm{~W} / \mathrm{m}^{2} / \mathrm{sr} / \mu \mathrm{m}$ for both cases). Also, the BT MAE in this region is less than $1.0 \mathrm{~K}$. It confirms the 536 accuracy of DART in this spectral region. 


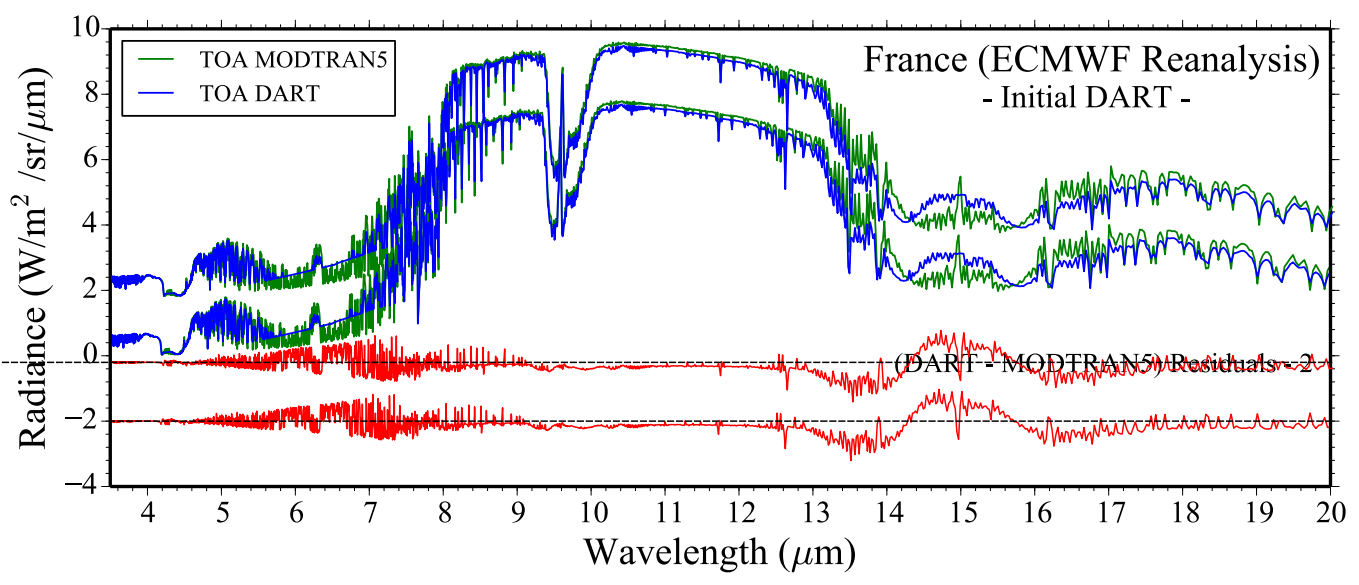

a)

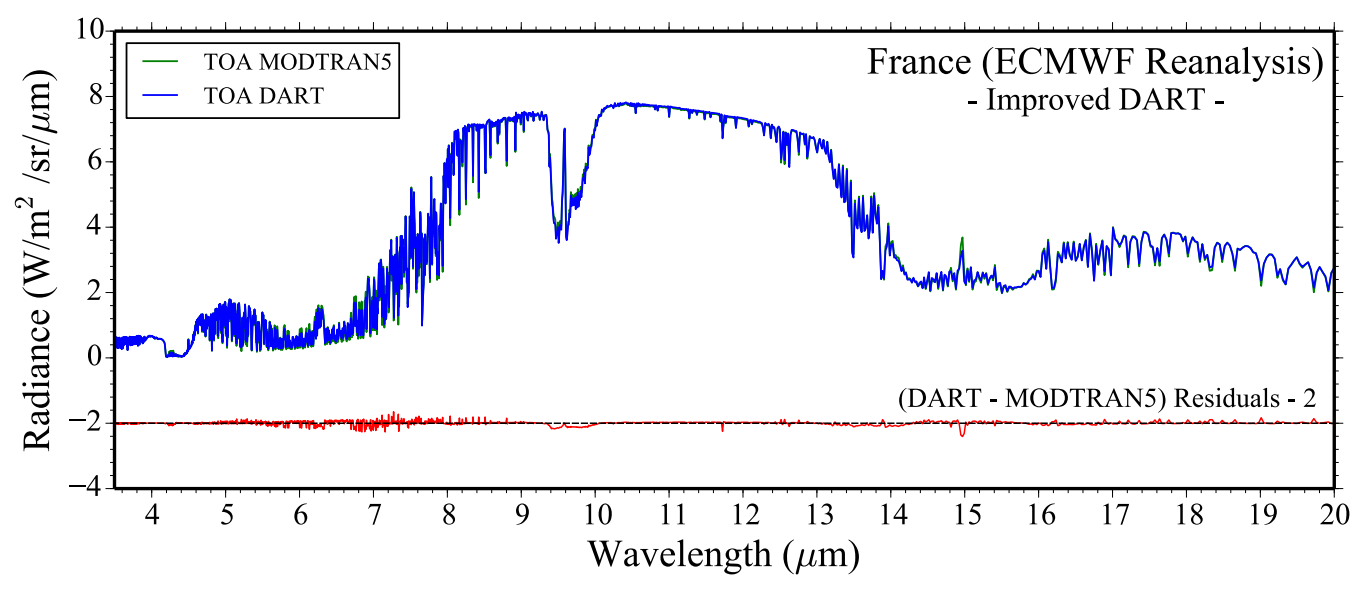

b)

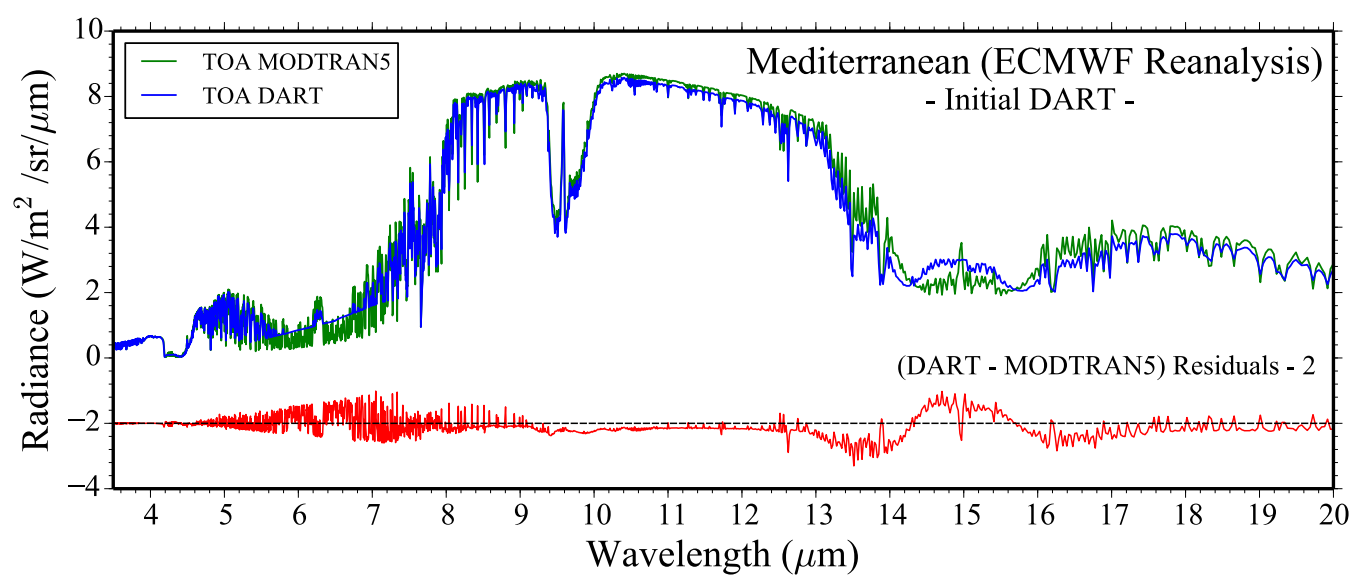

c) 


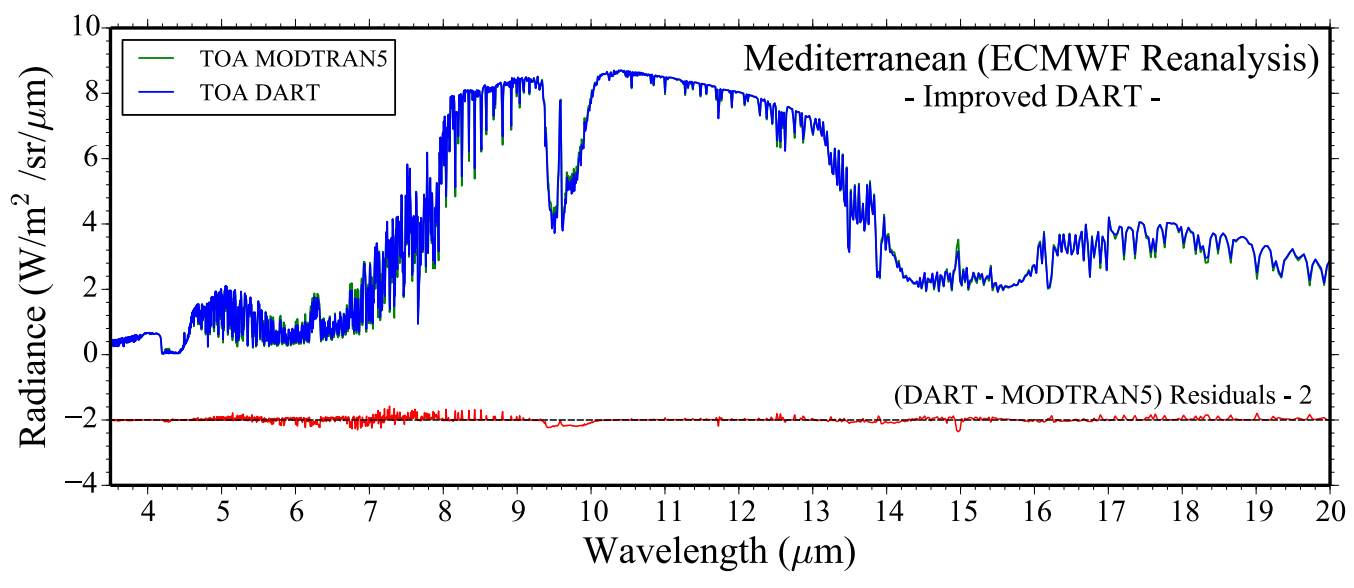

544 As indicated in section 4, gas equivalent absorption cross-sections $\sigma_{m_{i}}^{a}(\lambda, z)$ per atmosphere

Figure 12. TOA spectral radiance of initial $(a, c)$ and improved $(b, d)$ DART compared to MODTRAN5 with ECMWF reanalysis profile and surface parameter. a, b) France. c, d) Mediterranean Sea.

\subsection{Discussion}

altitude $z$ and gas $m_{i}$ are computed with Beer's law. However, Beer's law is less correct in the spectral bands with strong varying spectral absorption. In this case, the absorption extinction coefficient $\alpha_{j, m_{i}}^{a}(\lambda)$ computed by Eq. (9) is slightly smaller than the exact absorption extinction coefficient computed line-by-line, with a difference that depends on the number, strength and width of the absorption lines in the spectral bin. The small BT MAE with MODTRAN-5 validates our strategy. Indeed, if Beer's law is not obeyed, the slightly smaller absorption extinction coefficients lead to slightly lower radiation attenuation and thermal emission that tend to compensate each other, which explains that DART results are accurate. For oblique directions, the longer line-of-sight in each layer increases the issue. Therefore, errors increase with the obliquity of viewing direction at TOA. Conversely, at the BOA, errors decrease with the obliquity of the viewing direction. Indeed, at BOA, the underestimated attenuation

d) 
compensates the underestimated thermal emission because the downward vector sources

557 depend more on the thermal emission of the lower atmosphere layers if the line-of-sight is more 558 oblique.

560 The equivalent absorption cross-sections were pre-computed for six standard atmospheres that 561 are representative of most pressure and temperature profiles in different seasons over our planet. 562 It explains that DART can simulate accurate TOA radiance spectra for most user-defined 563 atmospheres using the modelling method presented in section 5.2. However, results are less 564 accurate if the actual atmosphere greatly differs from the six standard atmospheres since the 565 pre-computed equivalent absorption cross-sections are for temperature and pressure profiles of 566 standard atmospheres. Although pressure profiles are relatively stable over the Earth, 567 temperature profiles vary with time and space. For this reason, we investigated the variation of DART atmosphere thermal radiance accuracy if the atmosphere vertical profile is offset by $\Delta T$ at all altitude levels. Figure 13.a illustrates the impact of an offset equal to $+15 \mathrm{~K}$ for the USSTD76 atmosphere, in thermal emission mode, no aerosol, with Earth skin temperature $0 \mathrm{~K}$ and albedo 0.0. As expected, the offset increases the TOA BT MAE to $1.69 \mathrm{~K}$, especially in the

$572[10 \mu \mathrm{m}, 13 \mu \mathrm{m}]$ region where the DART adjustment method (Eq. (15)) overestimates vertical optical depth, which leads to overestimated atmospheric TIR radiance. Table 9 shows the MAE of TOA atmospheric TIR radiance of the USSTD76 atmosphere with five temperature offsets

$575 \Delta T=3 \mathrm{~K}, 6 \mathrm{~K}, 9 \mathrm{~K}, 12 \mathrm{~K}$ and $15 \mathrm{~K}$. Results are still accurate if the temperature offset relative 576 to the standard atmosphere is not too large. For example, TOA BT MAE is $1.07 \mathrm{~K}$ if $\Delta T=6 \mathrm{~K}$ 577 and $1.27 \mathrm{~K}$ if $\Delta T=9 \mathrm{~K}$.

579 We must note the errors in Table 9 decrease if the Earth surface thermal emission and scattering 580 are considered. For example, Figure 13.b shows the DART and MODTRAN-5 TOA total 
radiance spectra of the USSTD76 atmosphere with $+15 \mathrm{~K}$ temperature offset, and a land surface

582 with a skin temperature of $303.1 \mathrm{~K}$ (BOA temperature of the USSTD76 atmosphere with +15

$583 \mathrm{~K}$ offset) and an albedo of 0.14 (global annual average albedo of the Earth's surface in 2019

584 derived from ERA-Interim dataset). Results are much better, with TOA BT MAE equal to 1.1

$585 \mathrm{~K}$. Indeed, in the $[10 \mu \mathrm{m}, 13 \mu \mathrm{m}]$ region, the overestimated vertical optical depth slightly

586 reduces the contribution of Earth surface thermal emission on TOA radiance. Then, the

587 underestimated Earth thermal emission compensates the overestimated atmospheric thermal

588 emission and the total TOA radiance is better.

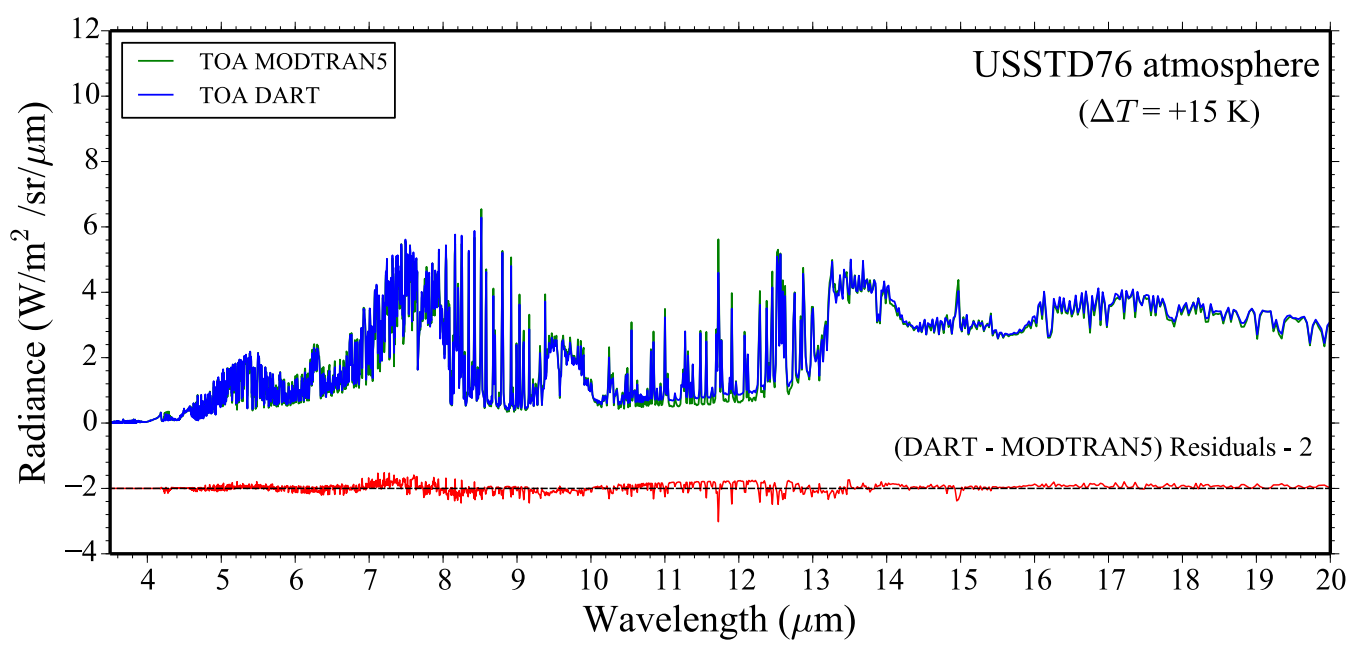

a)

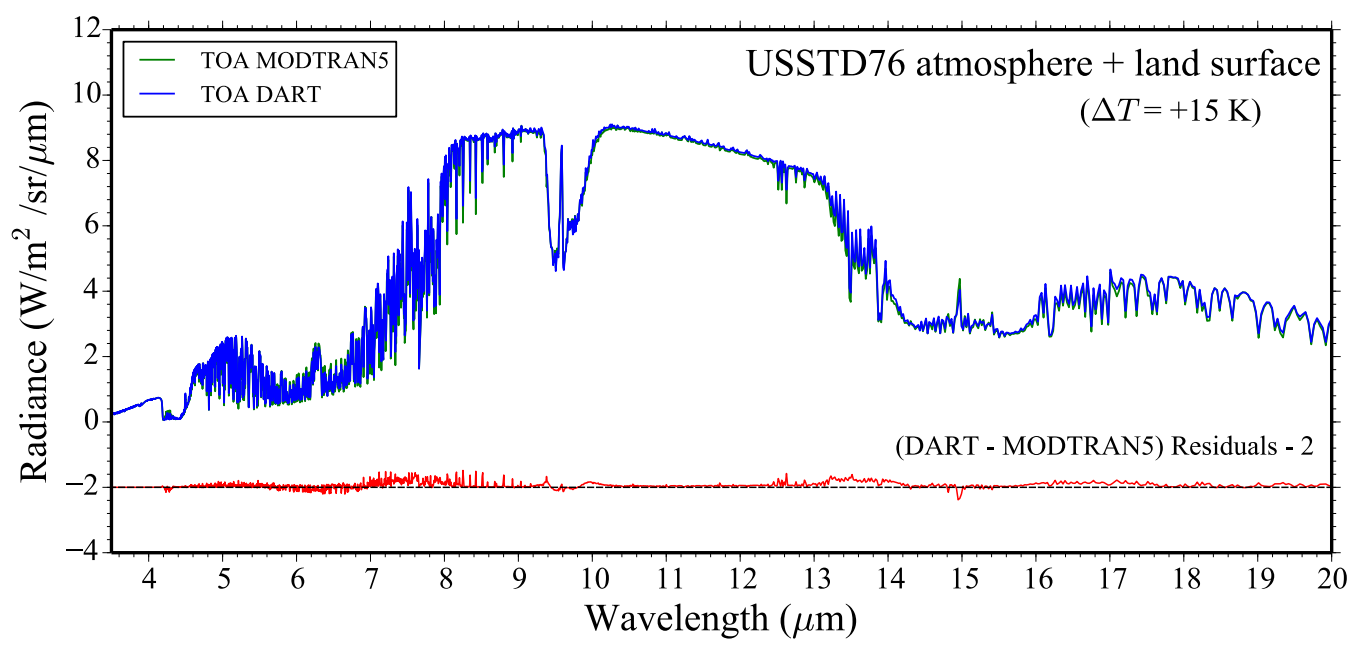




\begin{tabular}{ccccccc} 
profile. \\
\multicolumn{1}{c}{$0 \mathrm{~K}$} & $+3 \mathrm{~K}$ & $+6 \mathrm{~K}$ & $+9 \mathrm{~K}$ & $+12 \mathrm{~K}$ & $+15 \mathrm{~K}$ \\
\hline$\Delta T$ & & & & & & \\
\hline BT MAE $(\mathrm{K})$ & 0.68 & 0.87 & 1.07 & 1.27 & 1.48 & 1.69 \\
\hline
\end{tabular}

Figure 13. DART and MODTRAN-5 TOA TIR radiance spectra of the USSTD76 atmosphere with temperature vertical profile offset by $+15 \mathrm{~K}$. Atmosphere thermal emission only (a), total TOA thermal radiance with Earth surface thermal emission and scattering (b).

Table 9. TOA BT MAE of the USSTD76 atmosphere with six offsets $\Delta T$ of its temperature vertical profile.
595

604

605

606

607

608

609

610

\section{Concluding remarks}

DART TIR atmospheric RT modelling accuracy has been greatly improved by (1) introducing the equivalent absorption cross-section of the five most absorbing gases $\left(\mathrm{H}_{2} \mathrm{O}, \mathrm{CO}_{2}, \mathrm{O}_{3}, \mathrm{CH}_{4}\right.$, $\mathrm{N}_{2} \mathrm{O}$ ) in six standard atmospheres (USSTD76, TROPICAL, MIDDLATSUM, MIDDLATWIN, SUBARCSUM, SUBARCWIN), and (2) implementing a double-layer thermal emission modelling method. MODTRAN-5, with its atmospheric thermal BT accuracy better than $1 \mathrm{~K}$, is the reference atmospheric RT model to validate this improvement.

With the new RT modelling strategy, the TIR BT average MAE over the whole $[3.5 \mu \mathrm{m}, 20$ $\mu \mathrm{m}]$ region, for six standard atmospheres, decreased from $3.1 \mathrm{~K}$ to $0.71 \mathrm{~K}$ at TOA and from 2.1 $\mathrm{K}$ to $0.64 \mathrm{~K}$ at BOA, with largest improvements in the TIR absorbing regions (i.e., 3.5-4.5 $\mu \mathrm{m}$, 6-7 $\mu \mathrm{m}, 9-10 \mu \mathrm{m}, 14-16 \mu \mathrm{m})$. The band BT error in TIR bands of present and future EO satellite missions is also reduced below the NeDT of satellite TIR sensors. 
611 Sensitivity studies showed that DART atmospheric thermal radiance accuracy remains good $(<$

$6121 \mathrm{~K}$ ) for oblique viewing zenith angle less than $50^{\circ}$. This improvement was also verified with

613 atmospheric profiles and surface parameters from the ECMWF reanalysis dataset for two large

614 zones: France and Mediterranean Sea during summer. The average differences of TOA radiance

615 spectra with MODTRAN-5 decreased from $3.6 \mathrm{~K}$ to $1.0 \mathrm{~K}$ for the France summer atmosphere,

616 and from $3.7 \mathrm{~K}$ to $1.0 \mathrm{~K}$ for the Mediterranean Sea summer atmosphere. In the spectral region

617 over $3.5-5.0 \mu \mathrm{m}$ where the solar radiation contributes most to TOA radiance, the improved

618 DART still have accuracy better than $1.0 \mathrm{~K}$.

619

620 DART atmospheric thermal radiance is less accurate if the user-defined atmosphere 621 temperature profile differs from the six standard atmospheres, because DART uses temperature-dependent equivalent absorption cross-sections that are pre-computed for those standard atmospheres. However, the decrease in accuracy is relatively small. For example, TOA BT MAE only increases from $0.68 \mathrm{~K}$ to $1.07 \mathrm{~K}$ if the temperature profile of the USSTD76 atmosphere is offset by $+6 \mathrm{~K}$. In addition, the MAE decreases if the Earth surface thermal emission and scattering is considered. Future work will investigate a better adjustment method to compute accurate gas optical depth for arbitrary atmosphere profiles.

628

629 Due to its accurate TIR RT modelling both in the atmosphere and in 3D urban and natural 630 landscapes, including the Earth-atmosphere radiative coupling, DART meets the requirements 631 of TIR EO satellite missions (i.e., Trishna, Sentinel 3, Landsat 8/9) and LST applications in the 632 remote sensing community, which opens new perspectives for DART model. 
636 This work is funded by Région Occitanie Pyrénées-Méditerranée, France and the TOSCA

637 program of French Space Agency (CNES). We are also grateful for the support of DART team

638 scientists (Dr N. Lauret, J. Guilleux, E. Chavanon), and also to Dr A. Berk (Spectral Sciences,

639 USA) and Dr T. Yin (NASA, USA) for advices on MODTRAN-5 model.

640

641 Appendix. Nomenclature

642

\begin{tabular}{|c|c|}
\hline Symbols & Definitions \\
\hline$\Delta S$ & Surface \\
\hline$\Delta L$ & Horizontal path length \\
\hline$H$ & Scale height for major gases of an average atmosphere \\
\hline$\Omega$ & Direction vector \\
\hline$\Delta \Omega$ & Solid angle of direction $\Omega$ \\
\hline$\theta$ & Zenith angle \\
\hline$\mu$ & Shorthand of $\cos (\theta)$ \\
\hline$\varphi$ & Azimuth angle \\
\hline$\lambda$ & Wavelength \\
\hline$\Delta \lambda$ & Bandwidth \\
\hline$j$ & Index of atmosphere layer \\
\hline$J$ & Number of DART atmosphere layers \\
\hline$k$ & Index of virtual sub-layer \\
\hline$k_{j}$ & Number of virtual sub-layers in layer $j$ \\
\hline$z$ & Altitude \\
\hline$z_{j-1}$ & Lower boundary altitude of layer $j$ \\
\hline
\end{tabular}




\begin{tabular}{|c|c|}
\hline$Z_{j}$ & Upper boundary altitude of layer $j$ \\
\hline$\Delta z_{j}$ & Thickness of layer $j$ \\
\hline$\Delta z_{k}$ & Thickness of virtual sub-layer $k$ \\
\hline$Z_{m_{i}}^{*}$ & Specific height defined per gas $m_{i}$ such that under this altitude over $98 \%$ of \\
\hline & gas $m_{i}$ is concentrated. \\
\hline$h$ & Relative altitude within a layer $j$, with $h=0$ at bottom of layer and \\
\hline & $h=\Delta z_{j}$ at top of layer \\
\hline$T(z)$ & Temperature profile \\
\hline$\Delta T$ & Temperature offset \\
\hline$T_{j}(h)$ & Temperature at relative altitude $h$ in layer $j$ \\
\hline$T_{x}, T_{y}$ & Temperature variables in the double-layer method \\
\hline$T_{j}^{U}$ & Upper boundary temperature of layer $j$ \\
\hline$T_{j}^{L}$ & Lower boundary temperature of layer $j$ \\
\hline$T_{j}$ & Average temperature of layer $j$ \\
\hline$T_{k-1}$ & Lower boundary temperature of virtual sub-layer $k$ \\
\hline$T_{k}$ & Upper boundary temperature of virtual sub-layer $k$ \\
\hline$T_{D B}(z)$ & Temperature profile in DART atmosphere database \\
\hline$P(z)$ & Pressure profile \\
\hline$P_{D B}(z)$ & Pressure profile in DART atmosphere database \\
\hline$N(z)$ & Number density profile \\
\hline$N_{m}^{S}(z)$ & Number density profile of scattering gases \\
\hline$N_{m_{i}}(z)$ & Number density profile of gas $m_{i}$ \\
\hline$N_{m_{i}, D B}(z)$ & Number density profile of gas $m_{i}$ in DART atmosphere database \\
\hline$\rho_{m, D B}^{S}(z)$ & Relative density profile of scattering gases in DART atmosphere database \\
\hline
\end{tabular}




\begin{tabular}{|c|c|}
\hline$t_{m_{i}}^{a}(\lambda)$ & Vertical absorption transmittance of gas $m_{i}$ at wavelength $\lambda$ \\
\hline$t_{m_{i}}^{a}(\lambda, z, \Delta L)$ & $\begin{array}{l}\text { Absorption transmittance of gas } m_{i} \text { at wavelength } \lambda \text { along horizontal path } \Delta L \\
\text { at altitude } z\end{array}$ \\
\hline$t_{m_{i}, D B}^{a}(\lambda)$ & $\begin{array}{l}\text { Vertical absorption transmittance of gas } m_{i} \text { at wavelength } \lambda \text { in DART } \\
\text { atmosphere database }\end{array}$ \\
\hline$t_{m}^{S}(\lambda)$ & Vertical scattering transmittance of scattering gases at wavelength $\lambda$ \\
\hline$t_{m, D B}^{S}(\lambda)$ & $\begin{array}{l}\text { Vertical scattering transmittance of scattering gases at wavelength } \lambda \text { in DART } \\
\text { atmosphere database }\end{array}$ \\
\hline$\tau_{m_{i}}^{a}(\lambda)$ & Vertical absorption optical depth of gas $m_{i}$ at wavelength $\lambda$ \\
\hline$\tau^{s}(\lambda)$ & Vertical scattering optical depth of scattering gases at wavelength $\lambda$ \\
\hline$\tau_{p}(\lambda)$ & Vertical optical depth of aerosols at wavelength $\lambda$ \\
\hline$\tau_{p, D B}(\lambda)$ & $\begin{array}{l}\text { Vertical optical depth of aerosols at wavelength } \lambda \text { in DART atmosphere } \\
\text { database }\end{array}$ \\
\hline$\Delta \tau_{j}(\lambda)$ & Total optical depth of gases and aerosols of layer $j$ at wavelength $\lambda$ \\
\hline$\tau_{j-1}(\lambda)$ & Optical depth of gases and aerosols at bottom of layer $j$ at wavelength $\lambda$ \\
\hline$\tau_{j}(\lambda)$ & Optical depth of gases and aerosols at top of layer $j$ at wavelength $\lambda$ \\
\hline$\tau_{k-1}(\lambda)$ & $\begin{array}{l}\text { Optical depth of gases and aerosols at bottom of virtual sub-layer } k \text { at } \\
\text { wavelength } \lambda\end{array}$ \\
\hline$\tau_{k}(\lambda)$ & $\begin{array}{l}\text { Optical depth of gases and aerosols at top of virtual sub-layer } k \text { at wavelength } \\
\lambda\end{array}$ \\
\hline$\Delta \tau_{k}(\lambda)$ & $\begin{array}{l}\text { Total optical depth of gases and aerosols of virtual sub-layer } k \text { at wavelength } \\
\lambda\end{array}$ \\
\hline$\tau_{j}(\lambda, h)$ & Optical depth profile at wavelength $\lambda$ at relative attitude $h$ in layer $j$ \\
\hline$A_{j}(\lambda), B_{j}(\lambda)$ & Coefficients of optical depth function in layer $j$ at wavelength $\lambda$ \\
\hline
\end{tabular}


$C_{j}(\lambda), D_{j}(\lambda)$

$\alpha^{e} \quad$ Total extinction coefficient

$\alpha^{a} \quad$ Absorption extinction coefficient

$\alpha^{S} \quad$ Scattering extinction coefficient

$\alpha_{0}^{e} \quad$ Total extinction coefficient at bottom of atmosphere

$\alpha_{j, m_{i}}^{a}(\lambda) \quad$ Absorption extinction coefficient of gas $m_{i}$ of layer $j$ at wavelength $\lambda$

$\alpha_{j, m}^{a}(\lambda) \quad$ Gas absorption extinction coefficient of layer $j$ at wavelength $\lambda$

$\alpha_{j, m}^{S}(\lambda) \quad$ Gas scattering extinction coefficient of layer $j$ at wavelength $\lambda$

$\alpha_{j, m}^{e}(\lambda) \quad$ Gas total extinction coefficient of layer $j$ at wavelength $\lambda$

$\alpha_{j, p}^{a}(\lambda) \quad$ Aerosol absorption extinction coefficient of layer $j$ at wavelength $\lambda$

$\alpha_{j, p}^{s}(\lambda) \quad$ Aerosol scattering extinction coefficient of layer $j$ at wavelength $\lambda$

$\alpha_{j, p}^{e}(\lambda) \quad$ Aerosol total extinction coefficient of layer $j$ at wavelength $\lambda$

$\alpha_{p, D B}^{e}(z) \quad$ Aerosol total extinction coefficient profile at $550 \mathrm{~nm}$ in DART atmosphere database

$\alpha_{j}^{a}(\lambda) \quad$ Total absorption extinction coefficient of gases and aerosols of layer $j$ at wavelength $\lambda$

$\alpha_{j}^{s}(\lambda) \quad$ Total scattering extinction coefficient of gases and aerosols of layer $j$ at wavelength $\lambda$

$\alpha_{j}^{e}(\lambda) \quad$ Total extinction coefficient of gases and aerosols of layer $j$ at wavelength $\lambda$

$\alpha_{j}^{e}(\lambda, h) \quad$ Extinction coefficient profile of gases and aerosols at wavelength $\lambda$ at relative altitude $h$ in layer $j$

$\alpha_{z_{j-1}}^{e}(\lambda) \quad$ Total extinction coefficient of gases and aerosols at lower boundary of layer $j$ at wavelength $\lambda$ 


\begin{tabular}{|c|c|}
\hline$\alpha_{z_{j}}^{e}(\lambda)$ & $\begin{array}{l}\text { Total extinction coefficient of gases and aerosols at upper boundary of layer } j \\
\text { at wavelength } \lambda\end{array}$ \\
\hline$\sigma_{m_{i}}^{a}(\lambda)$ & Absorption cross-section of gas $m_{i}$ at wavelength $\lambda$ \\
\hline$\sigma_{m}^{S}(\lambda)$ & Gas scattering cross-section at wavelength $\lambda$ \\
\hline$\sigma_{m_{i}}^{a}(\lambda, z, \Delta L)$ & $\begin{array}{l}\text { Equivalent absorption cross-section of gas } m_{i} \text { at wavelength } \lambda \text { along } \\
\text { horizontal path } \Delta L \text { at altitude } z\end{array}$ \\
\hline$\sigma_{m_{i}}^{a(*)}(\lambda, z, \Delta L)$ & Rescaled $\sigma_{m_{i}}^{a}(\lambda, z, \Delta L)$ by dividing $\sigma_{m_{i}}^{a}(\lambda, z=0, \Delta L)$ \\
\hline$\sigma_{m_{i}}^{a}(\lambda, z)$ & $\begin{array}{l}\text { Equivalent absorption cross-section of gas } m_{i} \text { at wavelength } \lambda \text { along } \\
\text { horizontal path } \Delta L=7 \mathrm{~km} \text { at altitude } z\end{array}$ \\
\hline$\omega_{p, D B}(\lambda)$ & $\begin{array}{l}\text { Aerosol single scattering albedo at wavelength } \lambda \text { in DART atmosphere } \\
\text { database }\end{array}$ \\
\hline$\omega_{j}(\lambda)$ & $\begin{array}{l}\text { Single scattering albedo of mixed gases and aerosols of layer } j \text { at wavelength } \\
\lambda\end{array}$ \\
\hline$W_{j}(\Omega, \lambda)$ & Vector source of layer $j$ along direction $\Omega$ at wavelength $\lambda$ \\
\hline$W_{j}^{\uparrow}(\Omega, \lambda)$ & Upward vector source of layer $j$ along direction $\Omega$ at wavelength $\lambda$ \\
\hline$W_{j}^{\downarrow}(\Omega, \lambda)$ & Downward vector source of layer $j$ along direction $\Omega$ at wavelength $\lambda$ \\
\hline$L_{B}(T, \lambda)$ & Planck function at temperature $T$ at wavelength $\lambda$ \\
\hline$W_{\mathrm{ref}}^{\uparrow}(\Omega, \lambda)$ & $\begin{array}{l}\text { Spectrum of reference upward vector source along direction } \Omega \text { at wavelength } \\
\lambda\end{array}$ \\
\hline$\varepsilon$ & Threshold corresponds to MODTRAN decimal precision \\
\hline$q$ & Band index \\
\hline$Q$ & Number of spectral bands \\
\hline$X_{\mathrm{DART}}(q)$ & A type of DART product at band $q$ \\
\hline$X_{\text {MODTRAN }}(q)$ & A type of MODTRAN product at band $q$ \\
\hline
\end{tabular}




\begin{tabular}{cl}
\hline MAE & Mean absolute error \\
MARE & Mean absolute relative error \\
\hline
\end{tabular}

643

\section{References}

Abramowitz, M., Stegun, I.A., 1948. Handbook of mathematical functions with formulas, graphs, and mathematical tables. US Government printing office.

Anderson, G.P., Clough, S.A., Kneizys, F.X., Chetwynd, J.H., Shettle, E.P., 1986. AFGL atmospheric constituent profiles $(0.120 \mathrm{~km})$. AIR FORCE GEOPHYSICS LAB HANSCOM AFB MA.

Bento, V.A., DaCamara, C.C., Trigo, I.F., Martins, J., Duguay-Tetzlaff, A., 2017. Improving land surface temperature retrievals over mountainous regions. Remote Sens. 9, 38.

Berk, A., Anderson, G.P., Acharya, P.K., Bernstein, L.S., Muratov, L., Lee, J., Fox, M., AdlerGolden, S.M., Chetwynd, J.H., Hoke, M.L., 2005. MODTRAN 5: a reformulated atmospheric band model with auxiliary species and practical multiple scattering options: update, in: Algorithms and Technologies for Multispectral, Hyperspectral, and Ultraspectral Imagery XI. International Society for Optics and Photonics, pp. 662-667.

Berk, A., Anderson, G.P., Acharya, P.K., Shettle, E.P., 2008. MODTRAN5. 2.0. 0 user's manual. Spectr. Sci. Inc., Burlingt. MA, Air Force Res. Lab. Hanscom MA.

Berk, A., Bernstein, L.S., Robertson, D.C., 1987. MODTRAN: A moderate resolution model for LOWTRAN. SPECTRAL SCIENCES INC BURLINGTON MA.

Berk, A., Conforti, P., Hawes, F., 2015. An accelerated line-by-line option for MODTRAN combining on-the-fly generation of line center absorption within $0.1 \mathrm{~cm}-1$ bins and precomputed line tails, in: Algorithms and Technologies for Multispectral, Hyperspectral, and Ultraspectral Imagery XXI. International Society for Optics and Photonics, p. 947217. 
666 Bodhaine, B.A., Wood, N.B., Dutton, E.G., Slusser, J.R., 1999. On Rayleigh optical depth calculations. J. Atmos. Ocean. Technol. 16, 1854-1861.

668

669

670

671

672

673

674

675

676

677

678

679

680

681

682

683

684

685

686

687

688

689

690

Bonafoni, S., 2016. Downscaling of Landsat and MODIS land surface temperature over the heterogeneous urban area of Milan. IEEE J. Sel. Top. Appl. Earth Obs. Remote Sens. 9, 2019-2027.

Buehler, S.A., Mendrok, J., Eriksson, P., Perrin, A., Larsson, R., Lemke, O., 2018. ARTS, the Atmospheric Radiative Transfer Simulator-version 2.2. Geosci. Model Dev. 11, 15371556.

Clough, S.A., Iacono, M.J., Moncet, J., 1992. Line-by-line calculations of atmospheric fluxes and cooling rates: Application to water vapor. J. Geophys. Res. Atmos. 97, 15761-15785.

Clough, S.A., Shephard, M.W., Mlawer, E.J., Delamere, J.S., Iacono, M.J., Cady-Pereira, K., Boukabara, S., Brown, P.D., 2005. Atmospheric radiative transfer modeling: a summary of the AER codes. J. Quant. Spectrosc. Radiat. Transf. 91, 233-244.

Donlon, C., Berruti, B., Buongiorno, A., Ferreira, M.-H., Féménias, P., Frerick, J., Goryl, P., Klein, U., Laur, H., Mavrocordatos, C., 2012. The global monitoring for environment and security (GMES) sentinel-3 mission. Remote Sens. Environ. 120, 37-57.

Dugdale, S.J., 2016. A practitioner's guide to thermal infrared remote sensing of rivers and streams: recent advances, precautions and considerations. Wiley Interdiscip. Rev. Water $3,251-268$.

Ermida, S.L., Trigo, I.F., DaCamara, C.C., Roujean, J.-L., 2018. Assessing the potential of parametric models to correct directional effects on local to global remotely sensed LST. Remote Sens. Environ. 209, 410-422.

Gastellu-Etchegorry, J.-P., Demarez, V., Pinel, V., Zagolski, F., 1996. Modeling radiative transfer in heterogeneous 3-D vegetation canopies. Remote Sens. Environ. 58, 131-156.

Gastellu-Etchegorry, J.-P., Lauret, N., Yin, T., Landier, L., Kallel, A., Malenovský, Z., Al Bitar, 

A., Aval, J., Benhmida, S., Qi, J., 2017. DART: recent advances in remote sensing data modeling with atmosphere, polarization, and chlorophyll fluorescence. IEEE J. Sel. Top. Appl. Earth Obs. Remote Sens. 10, 2640-2649.

Gastellu-Etchegorry, J.-P., Yin, T., Lauret, N., Cajgfinger, T., Gregoire, T., Grau, E., Feret, J.B., Lopes, M., Guilleux, J., Dedieu, G., 2015. Discrete anisotropic radiative transfer (DART 5) for modeling airborne and satellite spectroradiometer and LIDAR acquisitions of natural and urban landscapes. Remote Sens. 7, 1667-1701.

Gastellu-Etchegorry, J.P., Martin, E., Gascon, F., 2004. DART: a 3D model for simulating satellite images and studying surface radiation budget. Int. J. Remote Sens. 25, 73-96.

Grau, E., Gastellu-Etchegorry, J.-P., 2013. Radiative transfer modeling in the EarthAtmosphere system with DART model. Remote Sens. Environ. 139, 149-170.

Guillevic, P., Gastellu-Etchegorry, J.P., Demarty, J., Prévot, L., 2003. Thermal infrared radiative transfer within three-dimensional vegetation covers. J. Geophys. Res. Atmos. 108.

Guillevic, P.C., Bork-Unkelbach, A., Göttsche, F.M., Hulley, G., Gastellu-Etchegorry, J.-P., Olesen, F.S., Privette, J.L., 2013. Directional viewing effects on satellite land surface temperature products over sparse vegetation canopies-A multisensor analysis. IEEE Geosci. Remote Sens. Lett. 10, 1464-1468.

He, J., Zhao, W., Li, A., Wen, F., Yu, D., 2019. The impact of the terrain effect on land surface temperature variation based on Landsat- 8 observations in mountainous areas. Int. J. Remote Sens. 40, 1808-1827.

Huang, H., 2018. Accelerated RAPID model using heterogeneous porous objects. Remote Sens. 10,1264

Irons, J.R., Dwyer, J.L., Barsi, J.A., 2012. The next Landsat satellite: The Landsat data continuity mission. Remote Sens. Environ. 122, 11-21. 
Jacquinet-Husson, N., Armante, R., Scott, N.A., Chédin, A., Crépeau, L., Boutammine, C., Bouhdaoui, A., Crevoisier, C., Capelle, V., Boonne, C., 2016. The 2015 edition of the GEISA spectroscopic database. J. Mol. Spectrosc. 327, 31-72.

Khanal, S., Fulton, J., Shearer, S., 2017. An overview of current and potential applications of thermal remote sensing in precision agriculture. Comput. Electron. Agric. 139, 22-32.

Kilpatrick, K.A., Podestá, G., Walsh, S., Williams, E., Halliwell, V., Szczodrak, M., Brown, O.B., Minnett, P.J., Evans, R., 2015. A decade of sea surface temperature from MODIS. Remote Sens. Environ. 165, 27-41.

Kobayashi, H., Iwabuchi, H., 2008. A coupled 1-D atmosphere and 3-D canopy radiative transfer model for canopy reflectance, light environment, and photosynthesis simulation in a heterogeneous landscape. Remote Sens. Environ. 112, 173-185.

Lagouarde, J.-P., Bhattacharya, B.K., Crebassol, P., Gamet, P., Babu, S.S., Boulet, G., Briottet, X., Buddhiraju, K.M., Cherchali, S., Dadou, I., 2018. The Indian-French Trishna mission: Earth observation in the thermal infrared with high spatio-temporal resolution, in: IGARSS 2018-2018 IEEE International Geoscience and Remote Sensing Symposium. IEEE, pp. 4078-4081.

Li, Z.-L., Tang, B.-H., Wu, H., Ren, H., Yan, G., Wan, Z., Trigo, I.F., Sobrino, J.A., 2013. Satellite-derived land surface temperature: Current status and perspectives. Remote Sens. Environ. 131, 14-37.

McCorkel, J., Montanaro, M., Efremova, B., Pearlman, A., Wenny, B., Lunsford, A., Simon, A., Hair, J., Reuter, D., 2018. Landsat 9 Thermal Infrared Sensor 2 Characterization Plan Overview, in: IGARSS 2018-2018 IEEE International Geoscience and Remote Sensing Symposium. IEEE, pp. 8845-8848.

Press, W.H., Teukolsky, S.A., Vetterling, W.T., Flannery, B.P., 2007. Numerical recipes 3rd edition: The art of scientific computing. Cambridge university press. 
741 Price, J.C., 1983. Estimating surface temperatures from satellite thermal infrared data-A 742 simple formulation for the atmospheric effect. Remote Sens. Environ. 13, 353-361.

743 Rothman, L.S., Gordon, I.E., Barbe, A., Benner, D.C., Bernath, P.F., Birk, M., Boudon, V., 744 Brown, L.R., Campargue, A., Champion, J.-P., 2009. The HITRAN 2008 molecular spectroscopic database. J. Quant. Spectrosc. Radiat. Transf. 110, 533-572.

746 Scott, N.A., 1974. A direct method of computation of the transmission function of an 747 inhomogeneous gaseous medium-I: Description of the method. J. Quant. Spectrosc.

Shettle, E.P., Fenn, R.W., 1979. Models for the aerosols of the lower atmosphere and the effects of humidity variations on their optical properties. Optical Physics Division, Air Force

752 753 Geophysics Laboratory.

Sobrino, J.A., Del Frate, F., Drusch, M., Jiménez-Muñoz, J.C., Manunta, P., Regan, A., 2016. Review of thermal infrared applications and requirements for future high-resolution sensors. IEEE Trans. Geosci. Remote Sens. 54, 2963-2972.

Verhoef, W., 1984. Light scattering by leaf layers with application to canopy reflectance modeling: The SAIL model. Remote Sens. Environ. 16, 125-141.

Vermote, E.F., El Saleous, N.Z., Justice, C.O., 2002. Atmospheric correction of MODIS data in the visible to middle infrared: first results. Remote Sens. Environ. 83, 97-111.

Vincent, R.A., Dudhia, A., 2017. Fast radiative transfer using monochromatic look-up tables. J. Quant. Spectrosc. Radiat. Transf. 186, 254-264.

Voogt, J.A., Oke, T.R., 2003. Thermal remote sensing of urban climates. Remote Sens. Environ. $86,370-384$.

Wang, K., Li, Z., Cribb, M., 2006. Estimation of evaporative fraction from a combination of day and night land surface temperatures and NDVI: A new method to determine the Priestley-Taylor parameter. Remote Sens. Environ. 102, 293-305. 
Wang, L., Qu, J.J., 2009. Satellite remote sensing applications for surface soil moisture monitoring: A review. Front. Earth Sci. China 3, 237-247.

Widlowski, J.-L., Lavergne, T., Pinty, B., Verstraete, M., Gobron, N., 2006. Rayspread: A virtual laboratory for rapid BRF simulations over 3-D plant canopies, in: Computational Methods in Transport. Springer, pp. 211-231.

Widlowski, J.-L., Mio, C., Disney, M., Adams, J., Andredakis, I., Atzberger, C., Brennan, J., Busetto, L., Chelle, M., Ceccherini, G., 2015. The fourth phase of the radiative transfer model intercomparison (RAMI) exercise: Actual canopy scenarios and conformity testing. Remote Sens. Environ. 169, 418-437.

Widlowski, J., Pinty, B., Lopatka, M., Atzberger, C., Buzica, D., Chelle, M., Disney, M., Gastellu-Etchegorry, J., Gerboles, M., Gobron, N., 2013. The fourth radiation transfer model intercomparison (RAMI-IV): Proficiency testing of canopy reflectance models with ISO-13528. J. Geophys. Res. Atmos. 118, 6869-6890.

Widlowski, J., Taberner, M., Pinty, B., Bruniquel-Pinel, V., Disney, M., Fernandes, R., Gastellu-Etchegorry, J., Gobron, N., Kuusk, A., Lavergne, T., 2007. Third Radiation Transfer Model Intercomparison (RAMI) exercise: Documenting progress in canopy reflectance models. J. Geophys. Res. Atmos. 112.

Willmott, C.J., Matsuura, K., 2005. Advantages of the mean absolute error (MAE) over the root mean square error (RMSE) in assessing average model performance. Clim. Res. 30, 7982.

Wiscombe, W.J., 1976. Extension of the doubling method to inhomogeneous sources. J. Quant. Spectrosc. Radiat. Transf. 16, 477-489.

\section{List of Figure Captions}


791 Figure 1. DART 3D mock-up and voxel matrix. Atmosphere is separated in three altitude 792 regions: high atmosphere (HA) made of layers, mid-atmosphere (MA) made of voxels of any 793 size, and bottom atmosphere (BA) in the Earth scene. Earth scene elements are made of facets 794 (triangles), and/or fluid and turbid vegetation voxels. The voxel matrix is introduced to optimize 795 ray tracing.

797 Figure 2. DART horizontally homogeneous atmosphere layer with layer thickness $\Delta z_{j}$. The 798 upper and lower boundary parameters are marked.

799

800 Figure 3. Major steps for modelling the RT in the Earth-atmosphere system. Red colour 801 indicates thermal emission (steps 1 and 2), orange colour indicates solar incident radiation, and 802 yellow colour indicates thermal and/or solar radiation that is scattered.

803

804 Figure 4. Initial DART and MODTRAN-5 TOA / BOA TIR radiance in [3.5 $\mu \mathrm{m}, 20 \mu \mathrm{m}]$ region 805 for USSTD76 (a), TROPICAL (b), MIDLATSUM (c) and SUBARCWIN (d) atmospheres. 1 806 $\mathrm{cm}^{-1}$ spectral resolution. DART and MODTRAN-5 configurations are detailed in section 3.

807

808 Figure 5. $\mathrm{CO}_{2}$ equivalent absorption cross-section $\sigma_{m_{i}}^{a}(\lambda, z, \Delta L)(\mathrm{a}, \mathrm{c})$ and rescaled equivalent 809 absorption cross-section $\sigma_{m_{i}}^{a(*)}(\lambda, z, \Delta L)(\mathrm{b}, \mathrm{d})$ at $13.4 \mu \mathrm{m}(\mathrm{a}, \mathrm{b})$ and $13.1 \mu \mathrm{m}(\mathrm{c}, \mathrm{d})$, in a $1 \mathrm{~cm}^{-1}$ 810 spectral bin, for 4 identical horizontal paths ( $\Delta L=1 \mathrm{~km}, 2 \mathrm{~km}, 5 \mathrm{~km}, 10 \mathrm{~km}$ ) at altitudes up to $81125 \mathrm{~km}$ for $13.4 \mu \mathrm{m}$ and up to $15 \mathrm{~km}$ for $13.1 \mu \mathrm{m}$, in the USSTD76 atmosphere.

813 Figure 6. Profiles of DART initial and improved absorption extinction coefficients in the 814 USSTD76 atmosphere. a) $10.0 \mu \mathrm{m}$. b) $13.0 \mu \mathrm{m}$. c) $15.4 \mu \mathrm{m}$. d) $19.6 \mu \mathrm{m}$. Spectral bin is $1 \mathrm{~cm}^{-1}$. 815 
816 Figure 7. DART atmosphere is made of $J$ layers, with layer optical depth $\Delta \tau_{j}$ and layer 817 thickness $\Delta z_{j}$. Each layer $j$ is virtually divided into $k_{j}$ sub-layers, with sub-layer thickness

$818 \Delta z_{k}=\frac{\Delta z_{j}}{k_{j}}$ and sub-layer optical depth $\Delta \tau_{k}$, with upper and lower boundary temperature $T_{k}$ and $819 T_{k-1}$, respectively.

820

821 Figure 8. Difference of DART double-layer upward vector source compared with the reference, 822 for various numbers of sub-layers. $T^{U}$ and $T^{L}$ are respectively the upper and lower boundary 823 temperatures. TRANS represents the layer transmittance. MARE is marked in the legend.

824

825

826

827 828 829

833

Figure 9. Improved DART and MODTRAN-5 TOA / BOA TIR radiance in [3.5 $\mu \mathrm{m}, 20 \mu \mathrm{m}]$ region for USSTD76 (a), TROPICAL (b), MIDLATSUM (c) and SUBARCWIN (d) atmospheres. $1 \mathrm{~cm}^{-1}$ spectral resolution. DART and MODTRAN-5 configurations are detailed in section 3 .

Figure 10. Improved DART and MODTRAN-5 TOA / BOA TIR radiance in [3.5 $\mu \mathrm{m}, 20 \mu \mathrm{m}]$ region for the USSTD76 atmosphere. Viewing zenith angle $\theta=30^{\circ}$ (a) and $\theta=60^{\circ}$ (b).

Figure 11. a) Vertical profiles of pressure (mb), temperature (K), and $\mathrm{H}_{2} \mathrm{O}, \mathrm{O}_{3}$ and $\mathrm{CO}_{2}$ number densities $(\mathrm{atm}-\mathrm{cm} / \mathrm{km})$ for three summer atmospheres: France, Mediterranean Sea and MIDLATSUM atmosphere. b) Maximum difference of vertical profiles.

Figure 12. TOA spectral radiance of initial $(a, c)$ and improved $(b, d)$ DART compared to MODTRAN-5 with ECMWF reanalysis profile and surface parameter. a, b) France. c, d) Mediterranean Sea. 
841 Figure 13. DART and MODTRAN-5 TOA TIR radiance spectra of the USSTD76 atmosphere

842 with temperature vertical profile offset by $+15 \mathrm{~K}$. Atmosphere thermal emission only (a), total 843 TOA thermal radiance with Earth surface thermal emission and scattering (b). 